\title{
Economic model predictive control for demand flexibility of a residential building
}

Finck, Christian ; Li, Rongling; Zeiler, Wim

\section{Published in:}

Energy

Link to article, DOI:

10.1016/j.energy.2019.03.171

Publication date:

2019

Document Version

Peer reviewed version

Link back to DTU Orbit

Citation (APA):

Finck, C., Li, R., \& Zeiler, W. (2019). Economic model predictive control for demand flexibility of a residential building. Energy, 176, 365-379. https://doi.org/10.1016/j.energy.2019.03.171

\section{General rights}

Copyright and moral rights for the publications made accessible in the public portal are retained by the authors and/or other copyright owners and it is a condition of accessing publications that users recognise and abide by the legal requirements associated with these rights.

- Users may download and print one copy of any publication from the public portal for the purpose of private study or research.

- You may not further distribute the material or use it for any profit-making activity or commercial gain

- You may freely distribute the URL identifying the publication in the public portal

If you believe that this document breaches copyright please contact us providing details, and we will remove access to the work immediately and investigate your claim. 


\section{Accepted Manuscript}

Economic model predictive control for demand flexibility of a residential building

Christian Finck, Rongling Li, Wim Zeiler

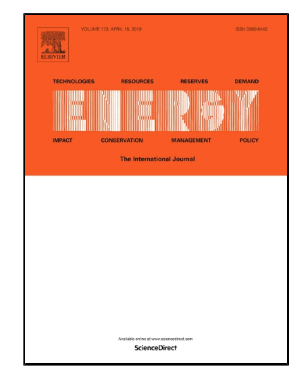

PII:

S0360-5442(19)30591-2

DOI:

10.1016/j.energy.2019.03.171

Reference:

EGY 15007

To appear in:

Energy

Received Date:

19 November 2018

Accepted Date:

28 March 2019

Please cite this article as: Christian Finck, Rongling Li, Wim Zeiler, Economic model predictive control for demand flexibility of a residential building, Energy (2019), doi: 10.1016/j.energy. 2019.03.171

This is a PDF file of an unedited manuscript that has been accepted for publication. As a service to our customers we are providing this early version of the manuscript. The manuscript will undergo copyediting, typesetting, and review of the resulting proof before it is published in its final form. Please note that during the production process errors may be discovered which could affect the content, and all legal disclaimers that apply to the journal pertain. 


\title{
Economic model predictive control for demand flexibility of a residential building
}

\author{
Christian Finck ${ }^{1 a}$, Rongling Li ${ }^{2}$, Wim Zeiler ${ }^{1}$
}

${ }^{1}$ Department of the Built Environment, Eindhoven University of Technology, de Rondom 705612 AP The Netherlands

${ }^{2}$ Department of Civil Engineering, Technical University of Denmark, Brovej, Building 118, 2800 Kgs. Lyngby, Denmark

${ }^{a}$ c.j.finck@tue.nl

\begin{abstract}
Future building energy management systems will have to be capable of adapting to variation in the rate of production of energy from renewable sources. Controllers employing a model predictive control (MPC) framework can optimise and schedule energy usage based on the availability of renewably generated energy. In this paper, an MPC using artificial neural networks (ANNs) was implemented in a residential building. The ANN-MPC was successfully tested and demonstrated good performance predicting the building's energy consumption. The controller was then modified to function as an economic MPC (EMPC) to optimise demand flexibility (i.e., the ability to adapt energy demands to fluctuations in supply). The operational costs of energy usage were associated with this demand flexibility, which was represented by three flexibility indicators: flexibility factor, supply cover factor, and load cover factor. The results from a day-long test showed that these flexibility indicators were maximised (flexibility factor ranged from -0.88 to 0.67 , supply cover factor from 0.04 to 0.13 , and load cover factor from 0.07 to 0.16 ) when the EMPC controller's demand flexibility was compared to that of a conventional proportional-integral (PI) controller. The EMPC framework for demand flexibility can be used to regulate on-site energy generation, grid consumption, and grid feed-in and can thus serve as a basis for overall optimisation of the operation of heating systems to achieve greater demand flexibility.
\end{abstract}

\section{Keywords}

Demand flexibility; Economic Model Predictive Control; Artificial Neural Network; optimal control; experimental case study; residential building

\section{Highlights}

- An ANN-MPC was developed and tested in a residential building.

- ANN models and an MPC framework were validated against measurements in buildings.

- An EMPC to maximise the demand flexibility of residential buildings was developed and tested. 


\section{INTRODUCTION}

In Europe, the share of primary energy supply from renewable sources increased to $14.2 \%$ in 2016 , which was the highest share for renewables among all regions in the Organisation for Economic Co-operation and Development (OECD) [1]. The large proportion of renewables requires added efforts to balance fluctuations and to maintain power quality and grid stability. As additional intermittently available sources of renewable energy - such as wind and solar - are included in the electricity infrastructure, it becomes essential to track and manage the dynamic behaviour of the demand side [2-7]. This ability to adapt to the intermittent availability of energy from renewable sources is called flexibility, and applies on both supply and demand sides [2-7]. The relevant literature [2-7] shows that there is a common understanding of the need for flexibility in energy systems. A review by Lund et al. [2], for example, identifies supply and demand flexibility as critical. The concept of demand flexibility is derived from the conventional method of load shifting and implies that demand flexibility should not compromise the quality and continuity of the processes that are consuming energy. DeConinck et al. [4] discussed the flexibility of buildings in terms of the magnitude and duration of load shifting. More precisely, a building's flexibility is described as its ability to deviate from a reference electric load profile [4]. Many studies have investigated the flexibility of buildings and have attempted to derive a common terminology and quantification scheme for building flexibility [7]. In 2015, the International Energy Agency's Energy in Buildings and Communities program launched its Annex 67 Energy Flexible Buildings project with these goals: to develop a common terminology for building's flexibility, to identify key performance indicators for characterising building's flexibility, and to quantify the potential flexibility of different buildings and clusters of buildings [7]. Early results from the Annex 67 project have shown that flexible energy usage in buildings includes different dimensions of flexibility, energy, power, and costs [5,7-9]. To ensure consistency in terminology, the present paper uses the term demand flexibility to represent the flexibility of buildings in adapting their energy demands to fluctuations in supply. Further insight into quantifying demand flexibility and its dimensions is provided in Section 1.1.

The potential for demand flexibility depends on the availability of end-uses that allow for such flexibility, such as electric vehicles and smart domestic appliances [7]. Other major sources of demand flexibility are the thermal and electrical loads for building heating, cooling, and ventilation [7]. To provide flexibility in their demands on the power grid, building heating, ventilation, and air conditioning (HVAC) installations make wide use of electrical power-to-heat systems and thermal energy storage systems [5,10,11]. In buildings, direct heating, combined heat and power systems (CHPs), and heat pumps (HPs) are the most common power-to-heat conversion technologies [9,12-14]. These can be combined with thermal energy storage (TES) options such as building thermal mass, water tanks, phase-change materials, or thermochemical storage systems $[5,15]$.

To increase demand flexibility, recent work has analysed the behaviour of building users $[6,16]$. The goal of the work is to progress beyond the physical characteristics of buildings, modelling, and measurements and to instead use occupants' perspectives [6]. A survey indicated that $11 \%$ of respondents may potentially become 
flexible in their use of energy. To raise awareness of flexibility among building users, the study [6] suggested, smart-technology adoption should be encouraged, and financial incentives should be provided.

\subsection{Review of quantification methods and key performance indicators of demand flexibility of buildings}

Reynders et al. $[8,17]$ give an overview of methodologies for quantifying demand flexibility of buildings in which they describe three dimensions of demand flexibility: size (energy), time (power), and costs. As an example, in a study by Nuytten et al. [13], energy flexibility is achieved by shifting electricity consumption in time. Reynders et al. [17] quantifies energy flexibility of different residential buildings in Belgium. Structural thermal energy storage has been used as a source of flexibility. Buildings with floor heating have a greater energy storage capacity than buildings with radiator heating. The researchers measured a storage efficiency of between $66 \%$ and $85 \%$ for non-renovated buildings. Stinner et al. [9] investigated power flexibility and proposed power curves that describe the evolution of power demand and availability over time. By defining a reference case and a maximal power curve, they simulated the maximum power flexibility for a building with CHP, HP, and TES. Junker et al. [18] introduce the flexibility function, which is a dynamic response to the energy consumption of a building. Based on a penalty control signal, the flexibility function represents a power-related flexibility stepresponse. De Conick et al. [4] investigated the $3^{\text {rd }}$ dimension of demand flexibility, the costs. They define cost curves for shifting the power demands of a building's HVAC system.

Salpakari et al. [19] investigated cost-optimal control of an HP, an electric boiler, and a water thermal energy storage system in an urban setting. Their simulation case study included low-order models implemented in optimal control indicating that an HP and electric boiler combined with TES can successfully enable load shifting, a reduction of operational costs of energy usage, and an increase in self-consumption (i.e., energy consumption from on-site generation). Operational electricity costs and self-consumption are typical performance indicators used when investigating demand flexibility. The studies by Clauß et al. [20] and Finck et al. [21] provide an overview of key performance indicators used to measure demand flexibility. They pay special attention to flexibility indicators that are used in the control of building energy systems. They find that conventional indicators such as operational energy costs and level of energy consumption are widely investigated in rule-based, optimal, and model predictive control. Indicators that describe flexibility such as load cover factor (self-generation), supply cover factor (self-consumption), flexibility factor, grid feed-in, available storage capacity, and storage efficiency [4,19,22-26], are primarily studied using rule-based control [20]. Clauß et al. [20] recommended conducting case studies to consider these specific flexibility indicators using optimal control. Péan et al. [27] present a similar conclusion, arguing that flexibility indicators need further investigation within the framework of model predictive control (MPC). Flexibility indicators may consequently be used as performance indicators in the framework of an MPC and economic MPC (EMPC), or even considered as control objective [27]. 


\subsection{Review of modelling methods, and key performance indicators of MPC implementations in buildings}

MPC controllers are becoming more widespread in energy management systems for buildings, because they optimally manage energy consumption through their use of weather forecasting and their prediction of the dynamics of a building's energy system [28-33]. However, they are more complex than conventional controllers, because they must periodically perform an online optimisation over a finite time horizon by modelling the entire building energy system. An MPC's prediction performance strongly depends on the modelling approach used to represent the building's energy system. Grey-box and black-box models have been identified as the most appropriate approaches [28]. For grey-box modelling, low-order resistance-capacitance networks are often used, which require less computational effort but exclude nonlinear characteristics [28]. In contrast, black-box models can cope with nonlinear behaviour but require sufficient data sets to be able to identify the dynamics of an energy system $[28,34,35]$. In recent years, artificial neural networks (ANNs) have been increasingly used as black-box models to represent building energy systems and to predict energy demand [34,36,37]. Afram et al. [34] provide a comprehensive overview of recent and successful implementations of ANNs with MPC, also called ANN-MPC. They find that ANN modelling improved performance of MPC-controlled HVAC subsystems. The use of ANN-MPC in real applications, experimental validations, and comparisons to conventional MPC including grey-box modelling methods - would help to increase the acceptance of ANN-MPC in buildings. However, Afram et al. [34] conclude that most studies that have applied ANN-MPC have considered residential complexes and commercial buildings rather than residential buildings. Wang et al. [38] reach a similar conclusion, judging that the reason for this may be the lack of monitoring data in residential buildings due to the unavailability of sensors and meters.

There have been few successful demonstrations of MPC implementations in buildings, because the financial benefits of MPC implementation are still smaller than the total costs $[39,40]$. The main challenges in designing a robust and resilient MPC which can be adapted to different buildings are the consideration of the stochastic nature of disturbances such as weather and occupancy, the effort and cost of modelling methods, and the conflicting nature of control objectives $[39,40]$. As an example for conflicting control objectives, in an experimental study from Killian et al. [39], optimal control was applied to an office building to minimize the primary energy consumption for heating and cooling while maximizing users' thermal comfort. A similar approach was taken by Viot et al. [41], using an MPC in an office building with a cost function that incorporated comfort (an optimal temperature within a comfort interval) and energy consumption costs. Sturzenegger et al. [42] implemented an office building HVAC system MPC which optimised the costs of operational energy usage and penalized comfort as constraint. Comfort as temperature bounds for MPC implementation was tested by Yu et al. [43], who used a climate chamber to investigate an MPC which minimized energy consumption for heating and cooling. In a study from Fiorentini et al. [30], an MPC was implemented in a residential building to demonstrate that available resources could be deployed to maximize systems efficiency while meeting occupant comfort. It can be noted that experimental investigations of MPC in buildings primarily consider energy 
costs, energy consumption, thermal comfort, and coefficient of performance (COP) as key performance indicators.

\subsection{Contribution and outline}

From the review of relevant literature it is clear that the development of MPC in buildings needs additional experimental investigation. Furthermore, a comparison of MPC implementations requires a comprehensive analysis of experimental results that show a multitude of performance indicators. This can be accomplished when all conventional indicators are presented, such as energy costs, energy consumption, thermal comfort, and COP. Additionally, to quantify demand flexibility in relation to the power grid, all relevant flexibility indicators need to be determined, so that conventional performance evaluation of MPC can be extended by evaluation of demand flexibility.

This study presents an implementation of MPC in a residential building. The study also shows how flexibility indicators can be associated with the costs of energy usage. Based on this, an EMPC is introduced to optimise demand flexibility. The contributions of this experimental case study can be summarised as follows:

- An ANN-MPC approach is implemented in a residential building and the prediction performance of the ANNs and the ANN-MPC is presented.

- Conventional performance indicators for MPC are determined, which are energy consumption, total cost of operational energy usage, and COP. Thermal comfort is represented by comfort bounds. Accordingly, the maximum and minimum room temperature are implemented as constraints in the MPC framework.

- Demand flexibility indicators are given: the flexibility factor, supply cover factor, and load cover factor.

- The study introduces an EMPC which enables the optimisation of performance indicators for demand flexibility and in which the operational costs of energy usage are associated with flexibility indicators.

The outline of the paper is as follows. Section 2 explains the methodology and the experimental case study. In Section 2.1, the test building is described. In Section 2.2, the MPC framework is presented. Section 2.2.2 provides insight into the identification procedure of black-box modelling using an ANN. The developed ANNs are integrated into the MPC framework. Section 2.3 introduces an EMPC for demand flexibility. The formulation of the EMPC includes different objective functions which can optimise the costs of energy usage associated with demand flexibility. The flexibility indicators and conventional performance indicators are also described in Section 2.3. The MPC framework and the EMPC are tested, and the results are shown in Section 3. 


\section{METHODOLOGY}

A Dutch residential building was used as a testbed to conduct the experimental case study of an EMPC approach that optimises the costs of energy usage associated with demand flexibility. The EMPC was implemented and tested during the heating season, between January and April 2017. The building heating system was equipped with a condensing boiler which distributes heat to radiator circuits. For modelling of the heating system and the building, ANN models were identified from measurements made between January and March 2017. In March and April 2017, the ANN models were validated and implemented in the MPC framework. The validation of the ANN-MPC was conducted based on heating consumption. In April 2017, the MPC was modified to EMPC (Figure 1), and photovoltaic (PV) panels were virtually installed the building to simulate on-site electricity generation. Additionally, an HP was virtually installed to simulate energy conversion from electricity to heating power. The virtual models of PV panels and the HP were implemented in the EMPC. Thus, the EMPC was simulated and tested with the energy system, including PV panels providing power that could be directly used by the HP and could be fed to the power grid, and an HP which was controlled to provide heating to the building. To investigate the optimisation of costs of energy usage associated with demand flexibility, the EMPC assumed (1) the costs of consuming electricity from the grid, (2) the costs of consuming electricity from on-site PV power generation, and (3) the costs delivering electricity from on-site PV power generation to the grid. Thus, the EMPC incorporates the costs of export of electricity and the costs of electricity consumption in one objective function. Accordingly, the most common indicators representing demand flexibility - the flexibility factor, supply cover factor, and load cover factor [21,44] - can be maximized while using an EMPC implementation that minimizes the total costs of energy usage. Two different EMPC approaches were introduced and tested. The EMPC approach 1 (EMPC1) maximised the flexibility factor and reduced the operational costs of electricity consumption. The EMPC approach 2 (EMPC2) maximised the flexibility factor, supply cover factor, and load cover factor and optimised the costs of electricity consumption from the grid, costs from on-site PV power generation, and costs for grid feed-in.

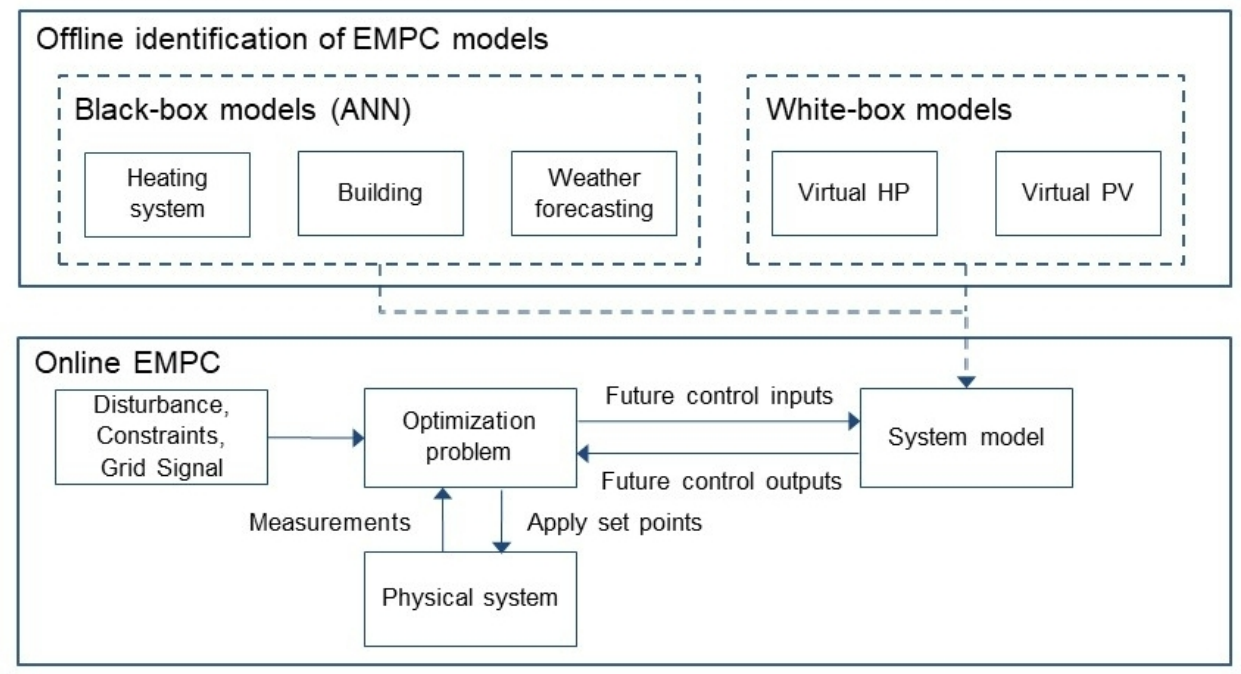

Figure 1. Methodological framework of the economic model predictive control (EMPC) controller. 
To simulate electricity consumption from the power grid, hourly day-ahead prices from the Amsterdam Power Exchange (APX) spot market were implemented in the EMPC. The key function of the EMPC approach is that the controller is designed to regulate an HP but, in reality, regulates a condensing boiler. Thus, the controller combines the identified heating system model and the HP model. The heating system model represents heating supplied to the building and the HP model represents the energy conversion from electricity to heating power. The dynamic behaviour of the HP is studied by [45-48]. The major differences to the condensing boiler are variations in the start-up and shut-down phases, which are neglected in this experimental case study to justify the usage of a virtual HP model.

\subsection{Building description}

The dwelling was located in the city of Utrecht, the Netherlands, representing a typical old row house from 1910 (Figure 2). During the test period, two persons lived in the dwelling. The dwelling was $75 \mathrm{~m}^{2}$ with three floors (kitchen on first floor, living room on second, bedroom on third). The building consisted of 25-cm outer and 15$\mathrm{cm}$ inner brick walls. With a $160^{\circ}{ }^{1}$ and $-20^{\circ}$ north-south orientation, the house was attached to neighbouring buildings. Due to the shading of the taller neighbouring building in the south, solar gains were limited (Figure 2). The windows at $-110^{\circ}$ and $70^{\circ}$ orientation captured solar radiation in the morning and afternoon. Windows in the living room had $50 \%$ single glazing and $50 \%$ double glazing; windows in the bedroom and kitchen had single glazing. Due to this large number of single-glazed windows, the thermal loads of the building were higher compared to those of renovated buildings. The annual heating energy usage was about $0.47 \mathrm{GJ} / \mathrm{m}^{2}$, which was delivered by a gas-fired condensing boiler. During cold periods when heating was required, the room temperature was controlled by one thermostat located on the second floor.

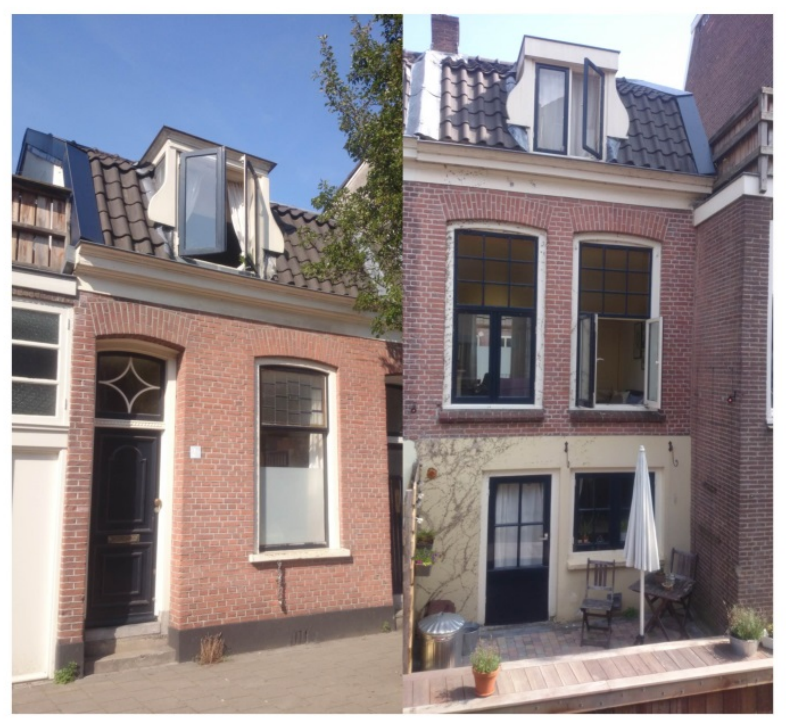

Figure 2. Test building located in Utrecht, the Netherlands (left-front view $-110^{\circ}$ orientation, right-back view $70^{\circ}$ orientation).

\footnotetext{
${ }^{1} 0^{\circ}=$ South orientation; $180^{\circ}=$ North orientation; $90^{\circ}=$ West orientation; $-90^{\circ}=$ East orientation
} 


\subsection{MPC framework}

A model predictive controller was implemented, enabling real-time control with hourly time steps $[30,38]$. A receding horizon of 12 hours was used for the MPC to regulate room temperature set points. Real-time measurements served as hourly starting points. The controller implemented upper and lower comfort bounds, which were based on occupants' preferences. Due to a deterministic occupancy profile $\epsilon_{t}$, the room temperature bounds were defined according to

$$
\begin{aligned}
& T_{\text {room }, \text { set }}=\left\{\begin{array}{l}
18 \leq T_{\text {room, set }}<22 \text { if } t \in(0: 00,8: 00) \\
20 \leq T_{\text {room, set }}<22 \text { if } t \in(8: 00,24: 00)
\end{array}\right\} \\
& \text { and } \\
& T_{\text {room,set }} \in \mathbb{Z} .
\end{aligned}
$$

The windows were closed during the test periods of MPC implementation. The opening of curtains was determined according to

$$
\text { Curtain opening }=\left\{\begin{array}{cc}
\text { Curtains }=0 & \text { (closed }) \text { if } t \in(0: 00,8: 00) \&(20: 00,24: 00) \\
\text { Curtains }=1 & \text { (open })
\end{array}\right\}
$$

where $t$ is the time (h). Because the MPC performed hourly simulations, a fast optimisation strategy was required. Dynamic programming (DP) was used as optimisation strategy and carried out in MATLAB. The DP algorithm handled the optimisation with sufficient computational times of less than $30 \mathrm{~min}$, because there was only one control variable, which was the average room temperature of the living room. During the computation of the optimisation at each control time step, first the duration of computation was estimated, then the simulation was run to predict 12 hours ahead. More information about the DP algorithm can be found in [49].

\subsubsection{Data acquisition and processing}

The model predictive controller required a modelling and simulation platform and a communication interface to sensors and actuators. All models that were associated with optimal control were implemented in a MATLAB scheme. MATLAB was also used to retrieve data from the sensors and to transfer commands to the thermostat. As middleware between MATLAB and the sensors, microcontrollers were placed in the building to catch information from the sensors and send them to the MATLAB controller. The microcontrollers were Arduino Yun modules that were connected to temperature sensors of type DC95 (thermistors) with an accuracy of $0.1{ }^{\circ} \mathrm{C}$. The temperature sensors measured room temperatures (six sensors placed at $1.20 \mathrm{~m}$ height), surface temperatures (three sensors placed at $1.20 \mathrm{~m}$ height), radiator temperatures (two sensors attached to radiators), heating return, and heating supply temperatures (two sensors attached to pipes). The constant flow rate of the heating system was determined using an ultrasonic flow meter to have a value of $0.8 \mathrm{~m}^{3} / \mathrm{h}$. 


\subsubsection{Model identification}

Comprehensive data sets were collected from measurements for the modelling of the building envelope, including all thermal zones, and the heating system. Furthermore, historical weather data were used to create the weather forecasting model, which predicted horizontal and global solar radiation and ambient temperature. Weather data and measurement data were used to validate the black-box models that were identified using ANNs. Previous case studies have successfully validated ANNs to identify building dynamics and building heating systems [34-36,50-53] and global and horizontal solar radiation [54-57]. In the present study, three neural networks were identified - an ANN for the building with all thermal zones, an ANN for the heating system, and an ANN for the solar radiation forecasting. All ANNs were developed using the MATLAB Neural Network toolbox. The identification of the ANNs was processed offline (Figure 1). Therefore, the data sets from measurements were randomly divided into three data sets which were used for training (70\%), validation (15 $\%)$, and testing (15\%). This procedure was repeated more than 100 times. Additionally, for the ANNs of the building and the heating system, a second validation step was performed using a set of unseen data. The performance prediction of the ANNs was statistically estimated by obtaining the root-mean-square error (RMSE), mean absolute error (MAE), mean absolute percentage error (MAPE), coefficient of determination $\left(R^{2}\right)$, and goodness of fit $(G)[34,35,52,58-60]$. The mathematical description of the performance metrics can be found in the Appendix.

\section{Weather forecasting}

The weather forecasting model predicted ambient temperature and global and horizontal solar radiation. The ambient temperature was retrieved from online forecasting [61] using a local network of 10 weather stations that were located within a radius of $2.5 \mathrm{~km}$ [54]. An online MATLAB connection was established, integrating an application programming interface (API) to the website [61]. Because forecasting of solar radiation was typically not provided by local weather forecasting, an ANN was developed to predict short-term solar radiation. The ANN considered for the solar radiation forecasting model was based on a feedforward network that consisted of input signals $u_{i}(i=1,2, \ldots, n)$, hidden layers, and output signals $y_{i}$ according to

$$
y_{i}=f\left(\sum_{i=1}^{n} w_{j i} u_{i}\right) .
$$

In the hidden layer, each neuron $j$ represented a sum of the input signals $u_{i}$ with a weighting factor $w_{j i}$ and connected to each output $y_{i}$ [55]. Based on local, historical weather data from the last 10 years [62], the ANN was trained using the input and output variables as shown in Figure 3. 


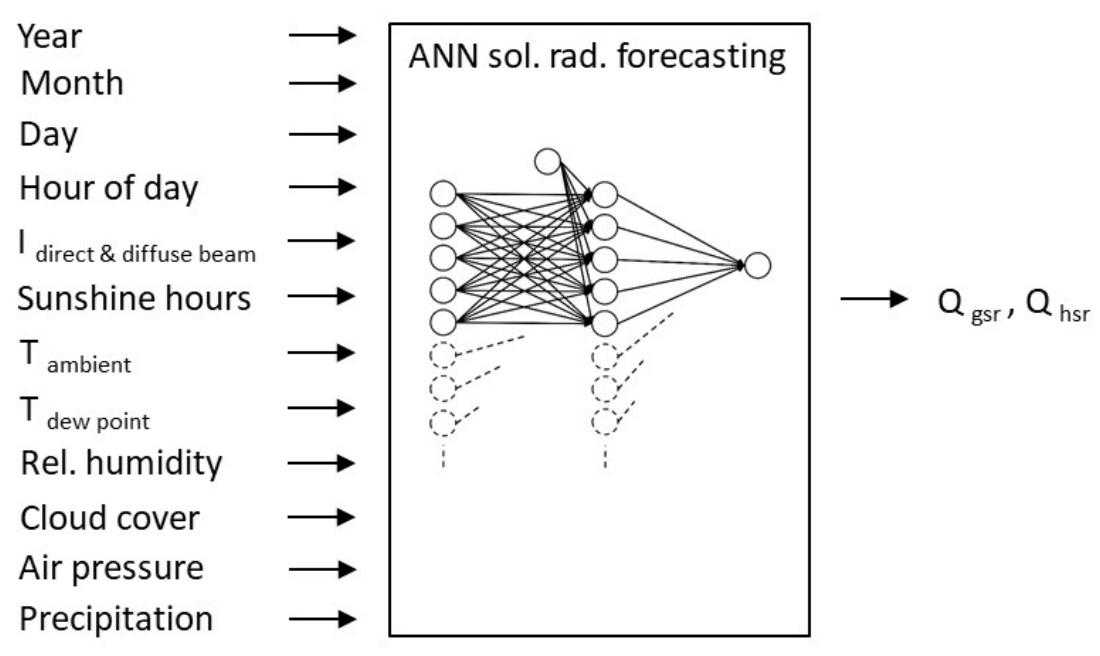

Figure 3. Inputs and outputs of artificial neural network (ANN) to obtain the global solar radiation (Qgsr) and horizontal solar radiation (Qhsr).

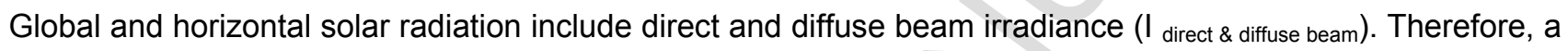
simplified clear sky model was used based on the work of Bird et al. [63]. For the ANN of solar radiation forecasting $\left(\mathrm{W} / \mathrm{m}^{2}\right)$, the best configuration was found with 75 hidden layers, resulting in a RMSE of 25, MAE of 13 , MAPE of $0.19, \mathrm{R} 2$ of 0.98 , and $\mathrm{G}$ of 0.87 , which were in good agreement with results from other studies $[56,64,65]$.

\section{Building and heating system}

The ANNs for the building (building envelope with all thermal zones) and heating system were based on timeseries problems that were nonlinear autoregressive with external (exogenous) input (NARX) problems. The NARX was a recurrent dynamic network using feedback connections according to

$$
y(t)=f\left(y(t-1), y(t-2), \ldots, y\left(t-n_{y}\right), u(t-1), u(t-2), \ldots, u\left(t-n_{u}\right)\right.
$$

where $y(t)$ is the output signal and $u(t)$ is the exogenous input variable [66]. Input and output variables of the ANNs are shown in Figure 4. During the heating period, only the living room was heated. Thus, the ANN for the building predicted the average thermal-zone temperature $T_{\text {room }}$ of the living room, the average surface temperature of the walls $T_{\text {surface, }}$ and the return temperature of the heating system $T_{\text {heating, return. }}$ As can be seen in Figure 4, 


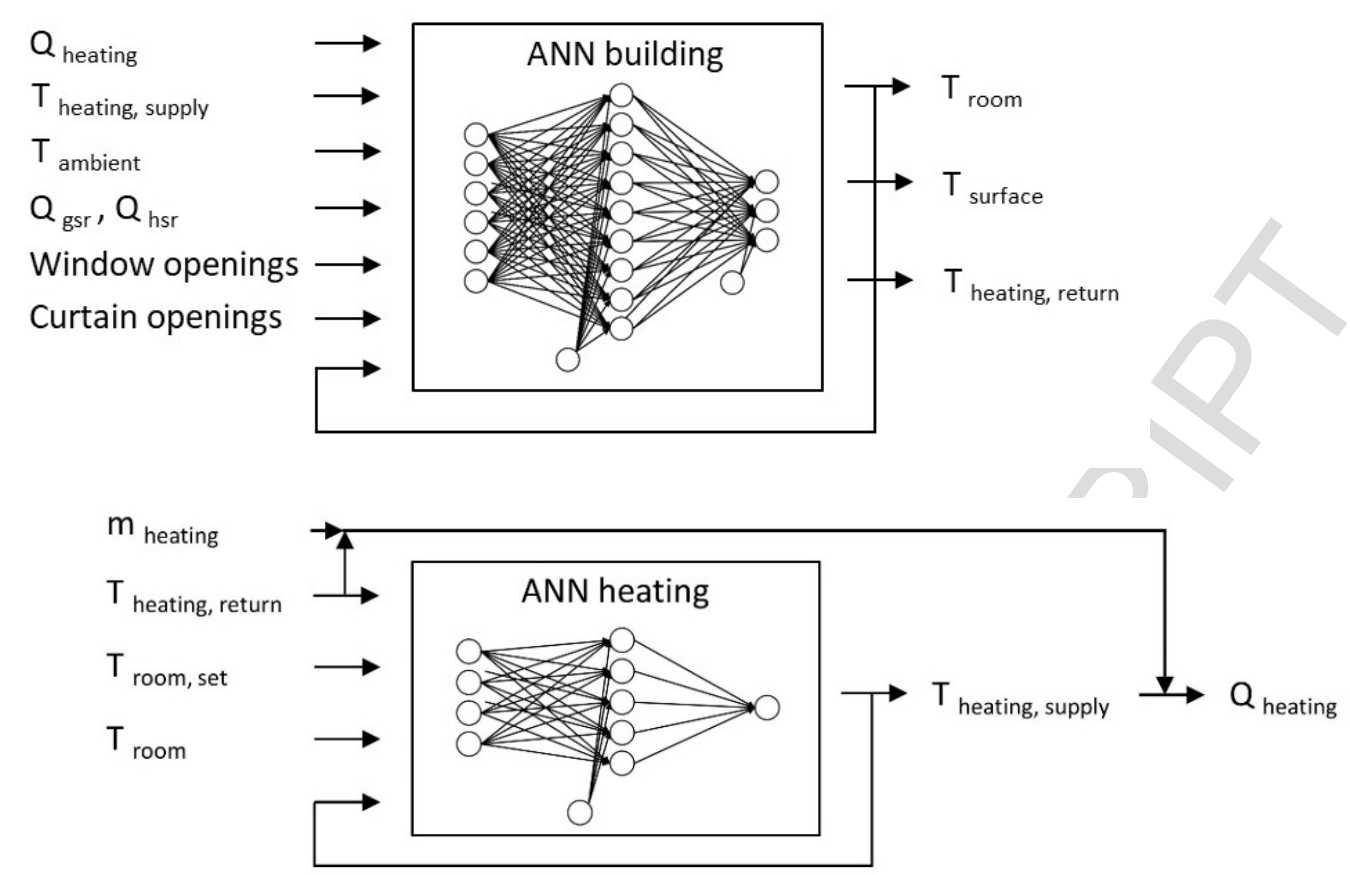

Figure 4. Inputs and outputs of artificial neural networks (ANNs) for the building and the heating system.

ANN inputs included the opening of windows and curtains. Measures of the opening of windows and curtains were recorded using a survey in which occupants filled in opening and closing times. The ANN for the heating system predicted the heating supply temperature so that the heating power could be calculated according to

$$
Q_{\text {heating }}=f\left(T_{\text {heating, return }} ; T_{\text {heating, supply }} ; \dot{m}_{\text {heating }}\right) .
$$

Measurement data were recorded with 1-s time steps. To train the ANNs, a 3-month data set with LevenbergMarquardt back-propagation was used. The data set for the identification was quite large compared with other studies, which identified ANNs based on data sets covering ranges of 10 days to 2 months $[34,36,50,67]$. The developed ANNs were applied to a validation set of unseen data (taken from 16 Mar. 2016 to 25 Mar. 2017), including temperature set point variations. The daily prediction performance is listed in Table 1 . The best configuration for the ANN building model was with two input delays, two feedback delays, and five hidden layers. For the ANN heating system, the best configuration had two input delays, two feedback delays, and eight hidden layers. The identified ANNs showed a good accuracy compared to the results from other studies that used black-box approaches for building-energy modelling [34-36,50,67]. 
Table 1. Daily performance of ANN models on 10 days of unseen data.

\begin{tabular}{ccccccc}
\hline & ANN & RMSE & MAE & MAPE & $\mathbf{R}^{2}$ & G \\
\hline $\begin{array}{c}\text { Heating } \\
\text { system }\end{array}$ & $\mathrm{Q}_{\text {heating }}(\mathrm{kWh})$ & $0.14-0.33$ & $0.03-0.10$ & $0.04-0.14$ & $0.98-0.99$ & $0.86-0.95$ \\
Building & $\mathrm{T}_{\text {room }}\left({ }^{\circ} \mathrm{C}\right)$ & $0.44-0.66$ & $0.32-0.53$ & $0.01-0.03$ & $0.78-0.89$ & $0.53-0.66$ \\
& $\mathrm{~T}_{\text {surface }}\left({ }^{\circ} \mathrm{C}\right)$ & $0.18-0.31$ & $0.14-0.25$ & 0.01 & $0.75-0.88$ & $0.50-0.65$ \\
& $\mathrm{~T}_{\text {heating, return }}\left({ }^{\circ} \mathrm{C}\right)$ & $0.57-0.87$ & $0.40-0.62$ & $0.01-0.02$ & $0.98-0.99$ & $0.88-0.92$ \\
\hline
\end{tabular}

\subsection{Economic MPC (EMPC)}

The online EMPC was implemented as shown in Figure 5. The EMPC approach imposed constraints and incorporated disturbances and control signals into the optimisation problem.

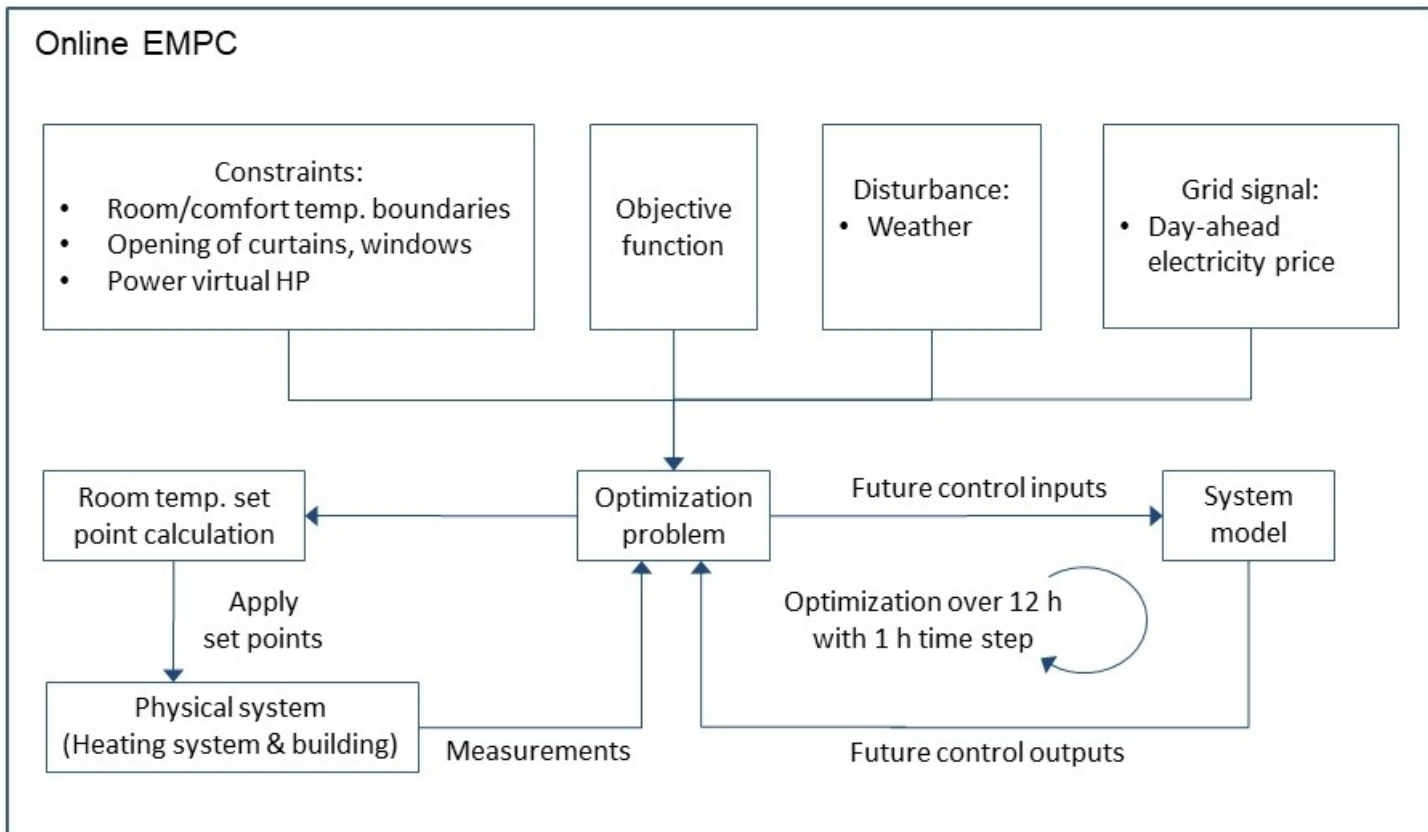

Figure 5. Online economic model predictive control (Online EMPC), adapted from Péan et al. [27].

The control decisions were retrieved from the system model which consists of black-box and white-box models. The black-box models were the ANNs for the building and heating system, and the white-box models virtually simulated the PV panels and the HP. The implementation of the models in the optimisation scheme is shown in Figure 6. 


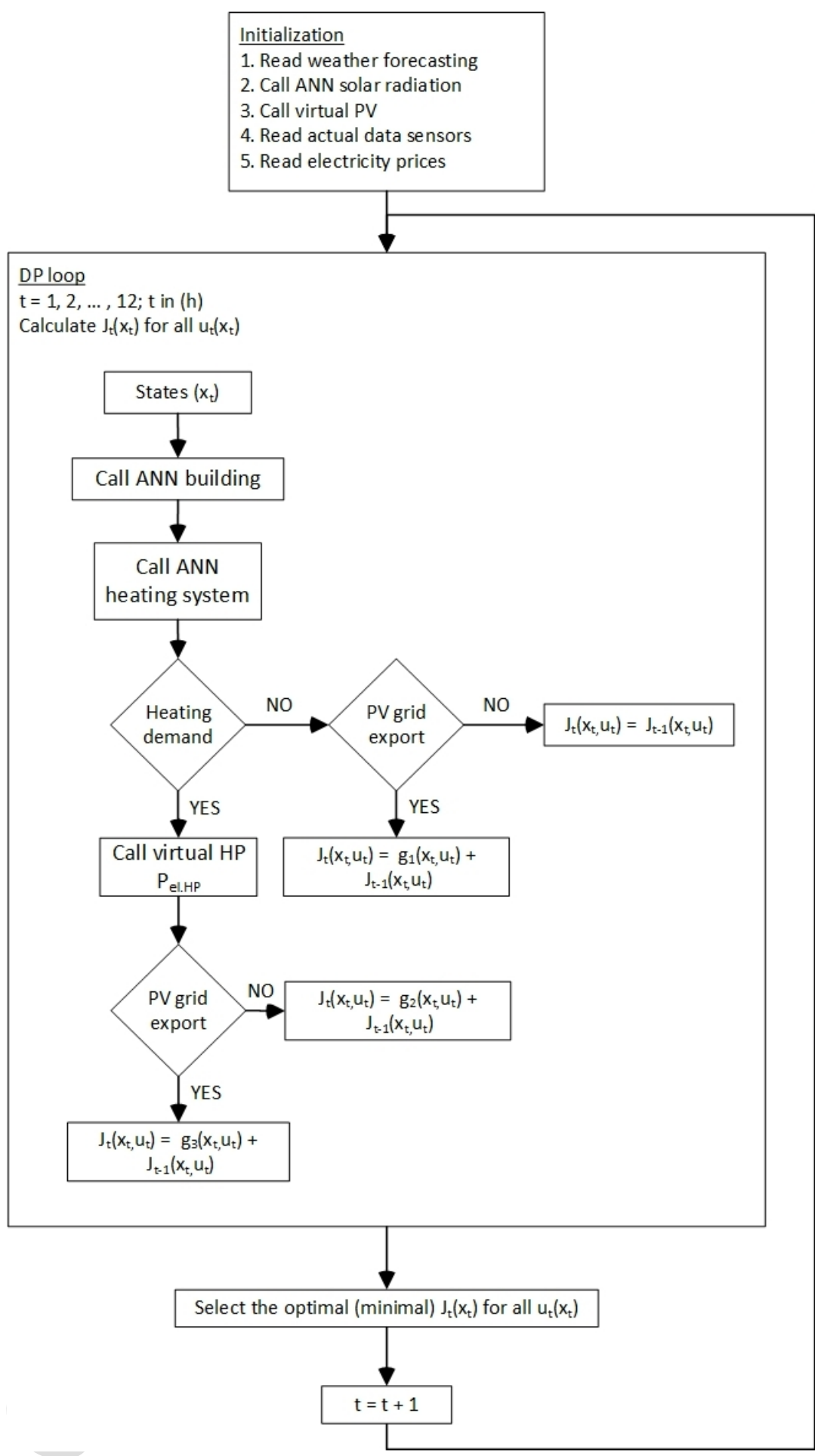

Figure 6. Simplified flowchart of optimal control decisions using dynamic programming (DP). 


\section{Heat pump (HP) model}

The heating power of the HP was limited to $20 \mathrm{~kW}$, which was the maximum heating power of the condensing boiler. The heating supply temperature of the HP reached a maximum of $65^{\circ} \mathrm{C}$, which was the maximum setting for the condensing boiler during the entire test period. The virtual HP was an inverter-controlled air-water HP from NIBE (NIBE2120) [68]. During the learning phase, the condensing boiler was set in Eco mode, which meant that the heating supply temperature was kept as low as possible, providing energy-efficient operation. This control strategy was similar to conventional HP strategies. Thus, the virtual HP model assumed energyefficient operation which was based on a piecewise linear interpolation function using manufacturers' data (Figure 7).

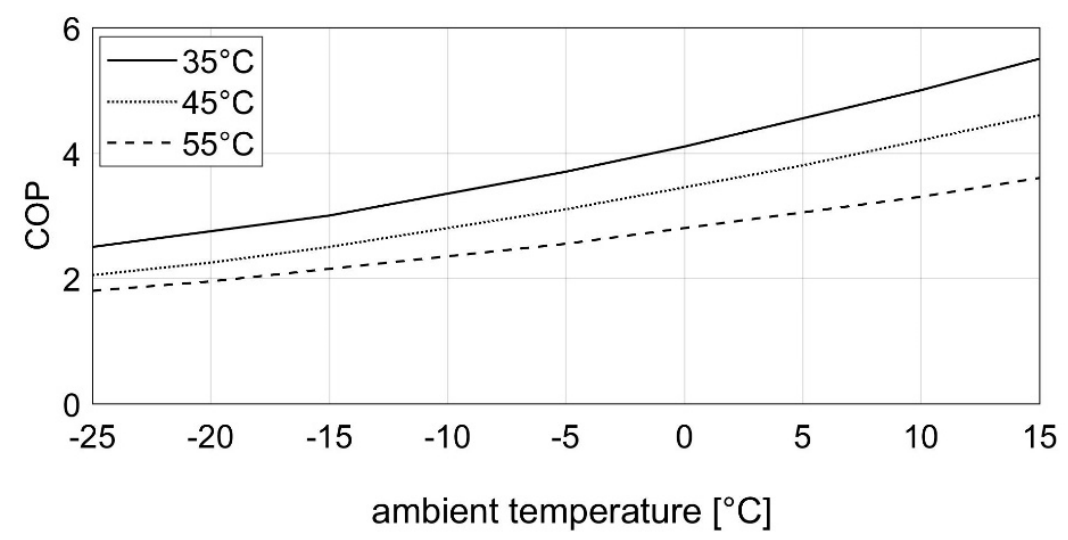

Figure 7. Performance of the air-water heat pump (HP); the coefficient of performance (COP) was a function of ambient temperature for different heating supply temperatures [68].

\section{Photovoltaic (PV) model}

PV panels were virtually placed on the roof of the building in a west-southwest (WSW) orientation measured $70^{\circ}$ from south orientation. As can be seen in Figure 2, the roof consisted of two areas with different inclinations: $47.5^{\circ}$ and $55^{\circ}$. PV panels were placed in both areas, resulting in a total PV area of about $13 \mathrm{~m}^{2}$. The chosen PV panels were mono-crystalline, with a nominal power of $300 \mathrm{~W}$ per module under standard test conditions (STC), in-plane-irradiation $G_{S T C}=1,000 \mathrm{~W} / \mathrm{m}^{2}$, and PV module temperature $T_{m o d, S T C}=25^{\circ} \mathrm{C}$ [69]. The PV model was based on the work of [70,71]. Power generation $Q_{\text {el.gen.PV }}$ and energy performance of the PV modules $\eta_{e l}$. were implemented in the MPC according to

$$
\begin{aligned}
& Q_{\text {el.gen.PV }}=Q_{e l . S T C} \frac{G}{G_{S T C}} \mathrm{\eta}_{e l .}\left(G^{\prime}, T^{\prime}\right), \\
& \eta_{e l .}=1+k_{1} \ln G^{\prime}+k_{2}\left(\ln G^{\prime}\right)^{2}+T^{\prime}\left(k_{3}+k_{4} \ln G^{\prime}+k_{5}\left(\ln G^{\prime}\right)^{2}\right)+k_{6} T^{\prime 2}, \\
& G^{\prime}=\frac{G}{G_{S T C}},
\end{aligned}
$$


and

$$
T^{\prime}=T_{\text {mod }}-T_{\text {mod }, S T C},
$$

where $G^{\prime}$ and $T^{\prime}$ are normalized irradiation and temperature. The coefficients $k_{1}-k_{6}$ depended on the type of $\mathrm{PV}$ panels and were taken from [70].

\section{Key performance indicators of EMPC}

This study presented conventional performance indicators and performance indicators for demand flexibility. The conventional indicators were energy consumption, operational energy costs, and the COP. For energy consumption, the HP used electricity from the grid and from PV panels. Additionally, the amount of heating provided by the HP was presented, and the resulting COP was retrieved according to Figure 7. The operational energy costs included (1) the costs of electricity consumption from the grid, (2) the costs related to electricity consumption from on-site PV power generation, and (3) the costs for grid feed-in from on-site PV power generation.

The performance indicators for demand flexibility were the flexibility factor, supply cover factor, and load cover factor. The flexibility factor $F F$ quantified heating energy provided by the HP during low-price and high-price periods for electricity according to

$$
F F=\frac{\int_{t_{\text {low pricestart }}}^{t_{\text {low price end }}} Q_{\text {heating }} d t-\int_{t_{\text {high price start }}}^{t_{\text {high price end }}} Q_{\text {heating }} d t}{\int_{t_{\text {low price start }}}^{t_{\text {lo price end }}} Q_{\text {heating }} d t+\int_{t_{\text {high pricestart }}}^{t_{\text {high }}} Q_{\text {heating }} d t}
$$

with $-1 \leq F F \leq 1$,

where $Q_{\text {heating }}$ is the amount of heating power. A flexibility factor of 1 indicated highest flexibility of the controlled system, and -1 correlated to inflexible energy usage. In the present study, the standard deviation was used to define high- and low-price periods according to [5]. Prices for energy consumption from the grid in periods above one standard deviation of $1 \sigma$ were considered as high-price periods, and prices in periods below one standard deviation of $-1 \sigma$ were low-price periods.

The degree of local power consumption covered by on-site electricity generation can be calculated using the load-matching indicators supply cover factor and load cover factor [22,25,72]. The supply cover factor $\gamma_{\text {supply }}$ (self-consumption) represents the ratio of direct consumption of $\mathrm{PV}$ electricity for heating $Q_{\text {el.cons.HP }-P V}$ and total PV electricity production $Q_{\text {el.gen.PV }}$ for a period $N$ according to

$$
\gamma_{\text {supply }}=\frac{\sum_{t=1}^{N} Q_{\text {el.cons.HP }-P V}}{\sum_{t=1}^{N} Q_{\text {el.gen.PV }}}
$$

with $0 \leq \gamma_{\text {supply }} \leq 1$ 
The load cover factor $\gamma_{\text {load }}$ (self-generation) represents the ratio of direct consumption of PV electricity for heating $Q_{\text {el.cons.HP - PV }}$ and total electricity heating demand $Q_{\text {el.cons.HP }}$ for a period $N$ according to

$$
\gamma_{\text {load }}=\frac{\sum_{t=1}^{N} Q_{\text {el.cons.HP }-P V}}{\sum_{t=1}^{N} Q_{\text {el.cons.HP }}}
$$

with $0 \leq \gamma_{\text {load }} \leq 1$

\subsubsection{EMPC1}

EMPC1 was designed to maximise demand flexibility as represented by the flexibility factor. A larger flexibility factor indicated a greater amount of HP-consumed electricity (provided for heating) shifting from high-price periods to low-price periods. The associated costs of energy usage were the costs of electricity consumption from the grid. Thus, EMPC1 attempted to minimize total costs $J_{E M P C 1}$ for the HP's operational electricity consumption from the grid $Q_{e l . c o n s . H P-g r i d}$ according to

$$
\min J_{E M P C 1}=\sum_{t=1}^{N}\left(C_{e l . c o n s . g r i d}(t) Q_{e l . c o n s . H P-g r i d}(t) \Delta t\right) ; \quad N=12 h ; \Delta t=1 h,
$$

where $C_{\text {el.cons.grid }}$ is the price of electricity consumption from the grid, which corresponded to hourly day-ahead prices from the APX spot market $[5,28,31,32]$. Costs related to electricity consumption from on-site PV power generation, and costs for grid feed-in from on-site PV power generation were not considered in EMPC1.

\subsubsection{EMPC2}

EMPC2 was designed to maximise demand flexibility as represented by the flexibility factor, the supply cover factor, and the load cover factor. As mentioned above, maximising the flexibility factor can be reached by minimising the total operational costs of energy consumption from the grid. Maximising the supply cover factor and load cover factor refers to an increase of self-consumption, or respectively an increase of electrical energy consumed from on-site PV power generation. On-site PV-generated electrical energy not used by the HP was exported to the power grid. Thus, EMPC2 required the inclusion of three different terms: (1) energy consumption from the grid, (2) energy consumption from on-site PV power generation, and (3) energy exported to the grid from on-site PV power generation. By accounting for the operational costs associated with each of these terms, one objective function was created which included costs for electricity consumption from the grid, costs for direct consumption of PV-generated power, and costs for grid feed-in. The study, therefore, introduced an EMPC for demand flexibility which was formulated as a minimisation problem according to 


$$
\begin{aligned}
& \min J_{E M P C 2}=\sum_{t=1}^{N}\left(C_{\text {el.cons.grid }}(t) Q_{\text {el.cons.HP-grid }}(t) \Delta t\right)+\sum_{t=1}^{N}\left(C_{\text {el.cons.PV }}(t) Q_{\text {el.cons.HP }-P V}(t) \Delta t\right) \\
& +\sum_{t=1}^{N}\left(C_{\text {el.feed in grid }}(t) Q_{\text {el.PV grid }}(t) \Delta t\right) ; \quad N=12 \mathrm{~h} ; \Delta t=1 \mathrm{~h},
\end{aligned}
$$

where $C_{\text {el.cons.grid }}$ is the price of electricity consumption from the grid, $C_{\text {el.cons.PV }}$ is the price of electricity consumption from on-site PV generation, and $C_{\text {el.feed in grid }}$ is the price of electricity exported to the power grid.

\subsubsection{Reference case}

A reference case was simulated to evaluate the results of EMPC1 and EMPC2. A 24-h period was simulated using a traditional $\mathrm{PI}$ controller according to

$$
T_{\text {room }, \text { set }, \text { ref }}=\left\{\begin{array}{l}
T_{\text {room,set,ref }}=18 \text { if } t \in(0: 00,8: 00) \\
T_{\text {room, set,ref }}=20 \text { if } t \in(8: 00,24: 00)
\end{array}\right\} .
$$

The results of the reference case simulation were compared to the measured and predicted results of EMPC1 and EMPC2. This comparison gave an indication of the performance of the two EMPC approaches as measured by heating energy consumption, costs for electricity consumption, the HP's COP, and demand flexibility. 


\section{RESULTS}

Experiments were carried out at the beginning of April 2017. Experimental results are shown for the validation of the MPC framework (3.1) and the application of the EMPC1 and EMPC2 (3.2). During the test days, hourly predictions of the ambient temperature were retrieved from local weather stations. Global and horizontal solar radiation was calculated based on the developed forecasting model (ANN sol. rad. forecasting). The MPC results are illustrated below, and measured data are compared to predicted data.

\subsection{Validation of MPC framework}

The model predictive controller was implemented and initially tested on 3 April 2017 between 8:00 and 12:00. During the validation period, solar radiation $\left(\mathrm{W} / \mathrm{m}^{2}\right)$ and ambient temperature $\left({ }^{\circ} \mathrm{C}\right)$ were measured and predicted. The results of the weather forecasting are illustrated in Figure 8. A prediction performance is calculated for ambient temperature of $\mathrm{RMSE}=0.34, \mathrm{MAE}=0.25$, and MAPE $=0.02$, and for hourly solar radiation of $\mathrm{RMSE}=25, \mathrm{MAE}=20$, and $\mathrm{MAPE}=0.06$.
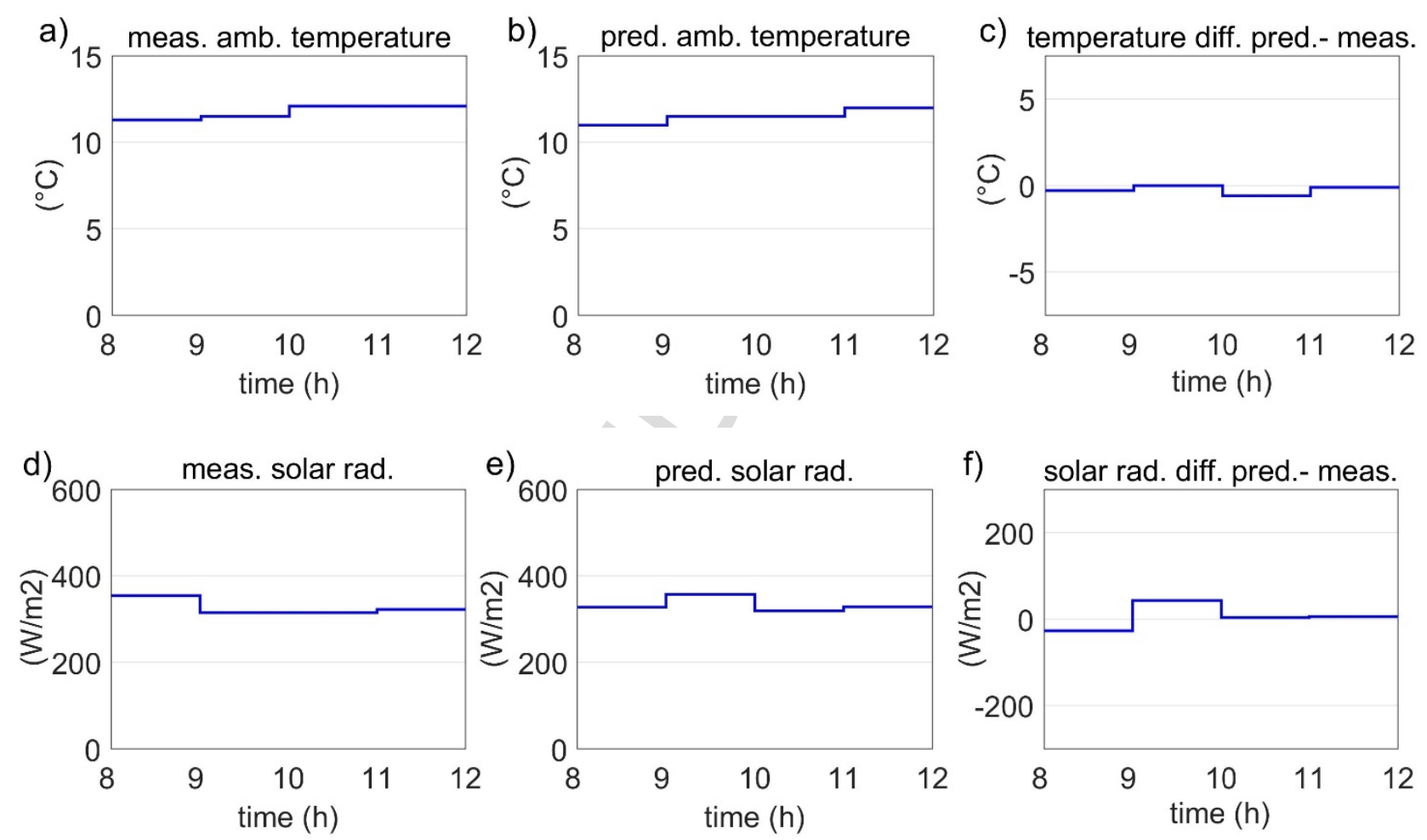

Figure 8. Validation of MPC; validation period 8:00 - 12:00; hourly ambient temperature a) measured, b) predicted, and c) difference; hourly solar radiation d) measured, e) predicted, and f) difference. 
For the validation period, a constant room temperature set point of $20^{\circ} \mathrm{C}$ was chosen. Measured and predicted room temperatures can be found in Figure 9. The measured average room temperature varied between $19.4^{\circ} \mathrm{C}$ and $20.1^{\circ} \mathrm{C}$, which is in accordance with the temperature range of historical data. The change in average room temperature was due to prevailing weather conditions and the transient interaction of room temperatures and wall temperatures. Using an ANN to simulate the room temperature resulted in a temperature curve that fit well to the measured data. A prediction performance was calculated for room temperature $\left({ }^{\circ} \mathrm{C}\right)$ of $\mathrm{RMSE}=0.14$, $\operatorname{MAE}=0.11$, and MAPE $=0.01$, and for heating demand $(\mathrm{kWh})$ of RMSE $=0.12, \operatorname{MAE}=0.11$, and MAPE $=$ 0.18 .
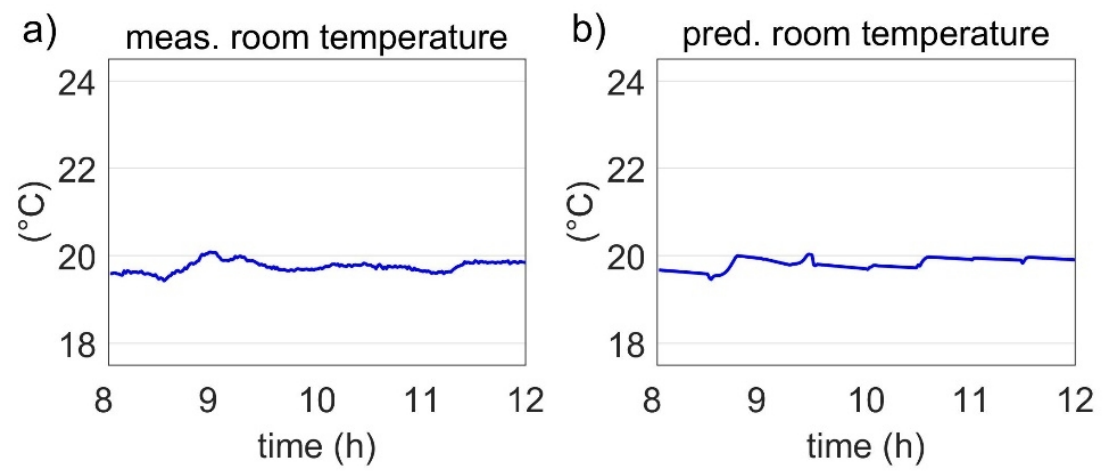

c) temperature diff. pred.- meas.
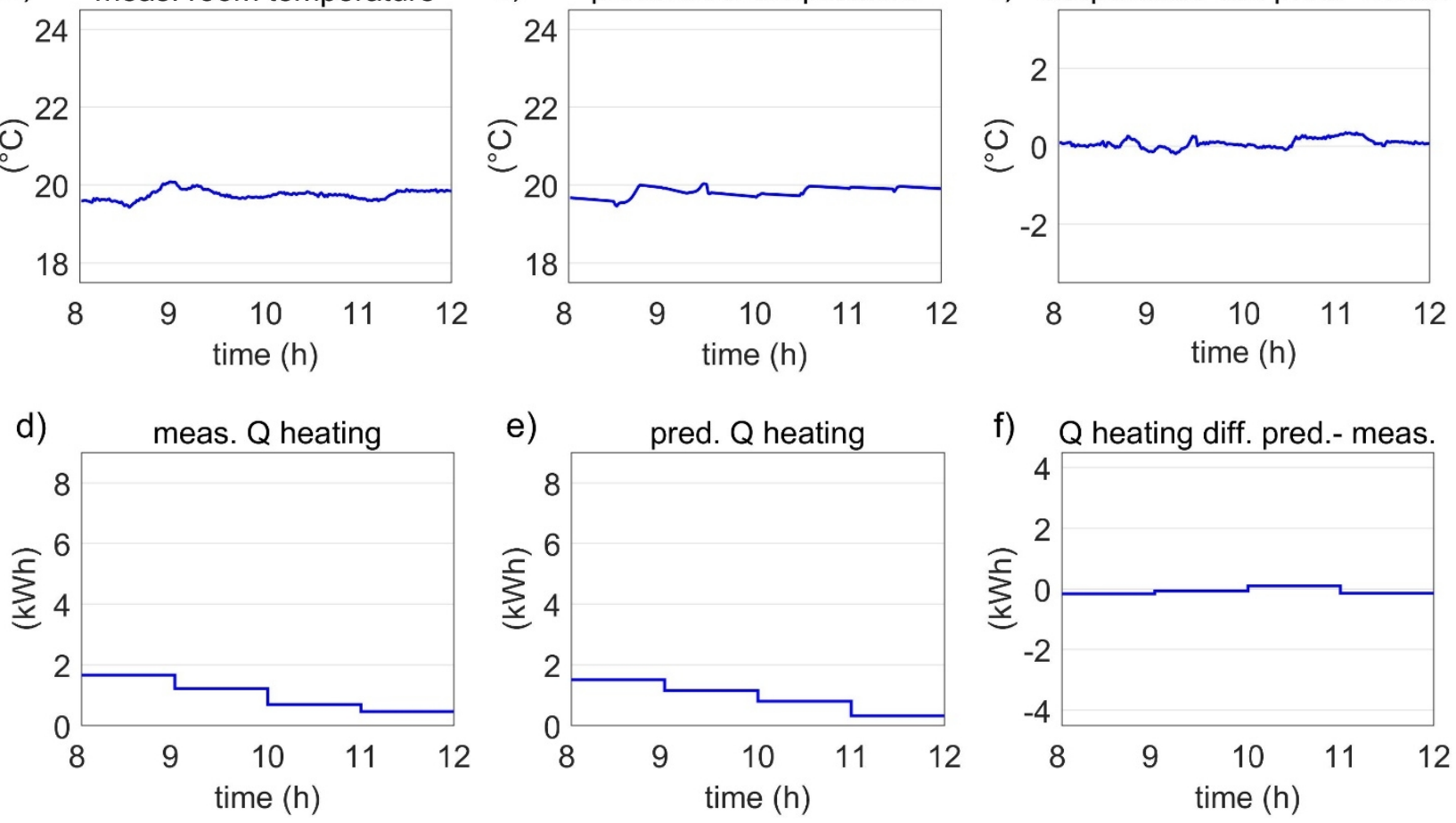

Figure 9. Validation of MPC; validation period 8:00 - 12:00; MPC results for a constant temperature set point of 20 ${ }^{\circ} \mathrm{C}$; average room temperature a) measured, b) predicted, and c) difference; hourly heating demand $\left(Q_{\text {heating }}\right) d$ ) measured, e) predicted, and f) difference.

\subsection{EMPC}

The MPC framework was modified to two EMPC approaches. Measured and predicted data were collected for a 24-h period (one day), and results were compared for flexibility indicators, daily energy consumption, and total costs of electricity consumption.

\subsubsection{EMPC1}

EMPC1, designed to maximise the flexibility factor, was implemented and tested on 05 April 2017. The results of hourly predictions and measurements taken for ambient temperature and solar radiation are depicted in 
Figure 10. A prediction performance was calculated for ambient temperature of $\mathrm{RMSE}=0.96, \mathrm{MAE}=0.77$, $\mathrm{MAPE}=0.07, \mathrm{R}^{2}=0.80, \mathrm{G}=0.55$ and for the hourly solar radiation of $\mathrm{RMSE}=37, \mathrm{MAE}=24, \mathrm{MAPE}=0.25$, $R^{2}=0.96$ and $\mathrm{G}=0.79$.
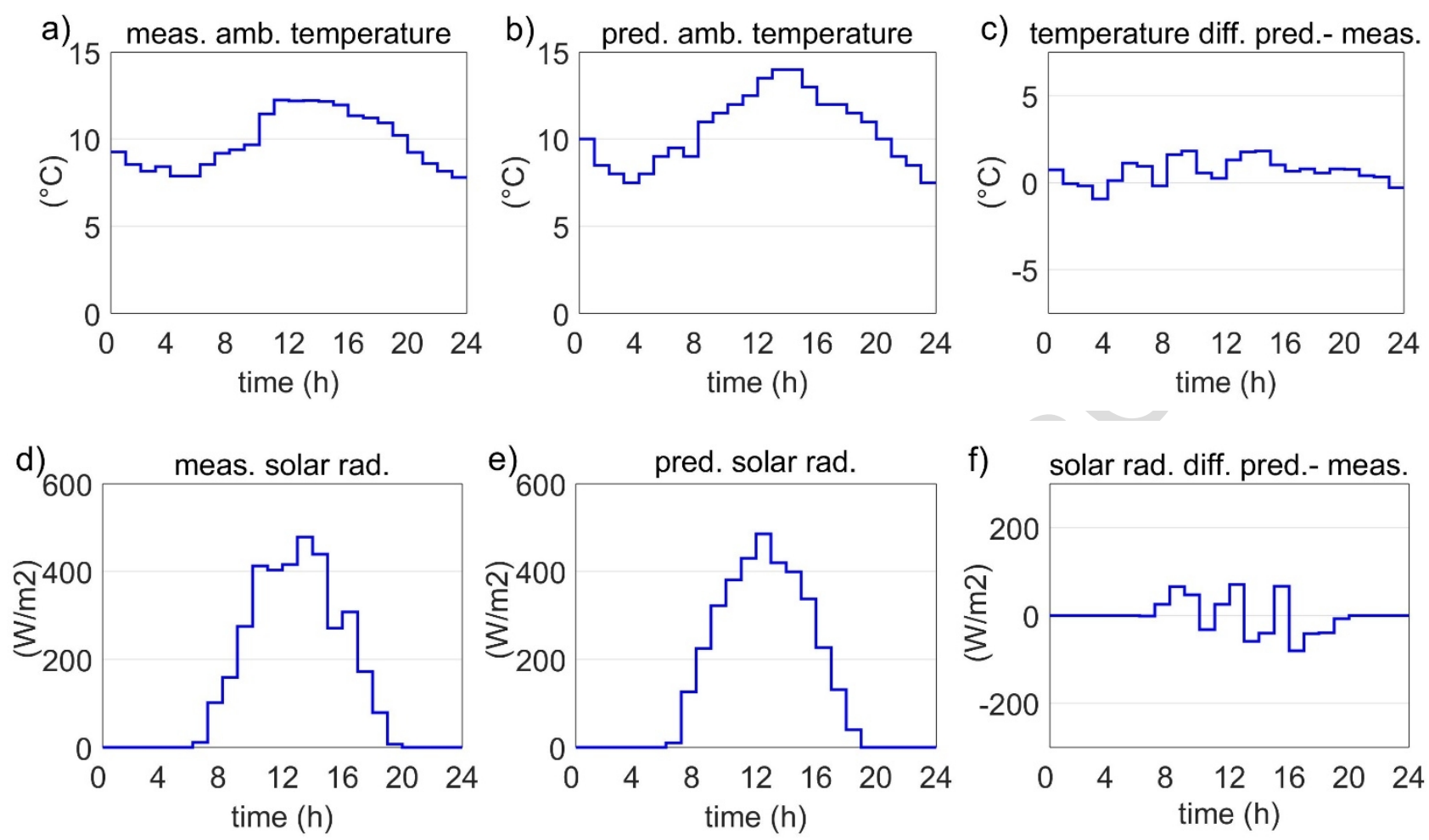

Figure 10. EMPC1; hourly ambient temperature a) measured, b) predicted, and c) difference; hourly solar radiation d) measured, e) predicted, and f) difference.

Based on hourly weather forecasting and hourly electricity prices, EMPC1 simulated the optimal control decisions for the operation of the room temperature set points. The results of those control decisions are illustrated in Figure 11. A prediction performance was calculated for room temperature of RMSE $=0.24$, MAE $=0.16, \mathrm{MAPE}=0.01, \mathrm{R}^{2}=0.89$, and $\mathrm{G}=0.66$ and for heating demand of RMSE $=0.26, \mathrm{MAE}=0.17, \mathrm{MAPE}=$ $0.30, R^{2}=0.97$, and $G=0.82$. Between 5:00 and 6:00, during low-price periods (Figure 11b), the HP was scheduled to provide heating to the building (Figure 11c). Due to preheating in low-price periods, only minimal heating consumption was required during high-price periods (Figure 11a). A summary of the test results using EMPC1 can be found in Table 2. Table 2 also lists the results of a simulated reference case using perfect weather prediction and feedback control. The results from EMPC1 indicate that total operational electricity costs were reduced by $7 \%$, and heating demand was increased by $1.5 \%$ when measured EMPC1 results were compared to the reference case. However, EMPC1 was designed to maximise the flexibility factor, which increased from -0.89 to 0.42 . 


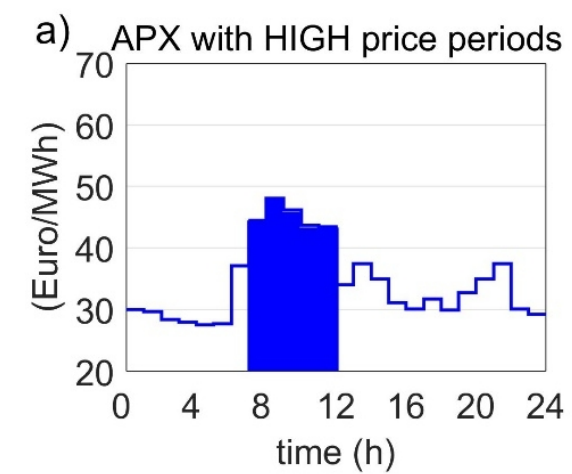

d) meas. room temperature

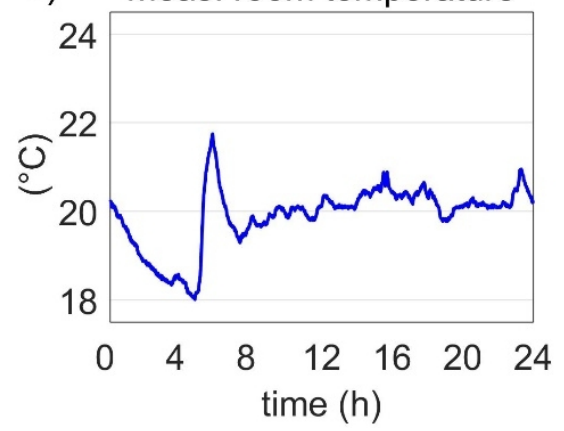

g)

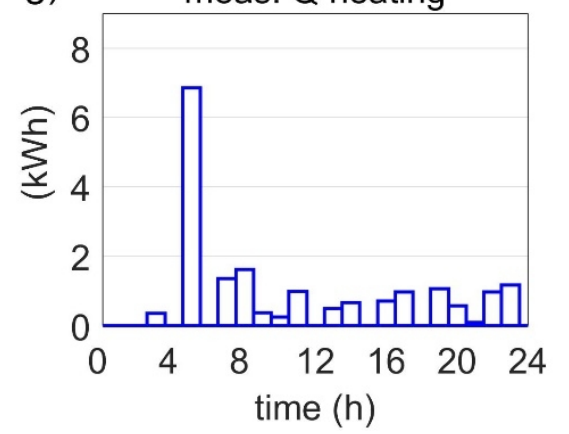

b) $\mathrm{APX}$ with LOW price periods

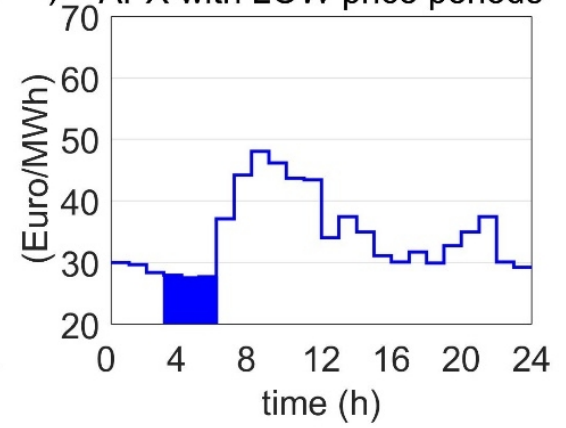

e)

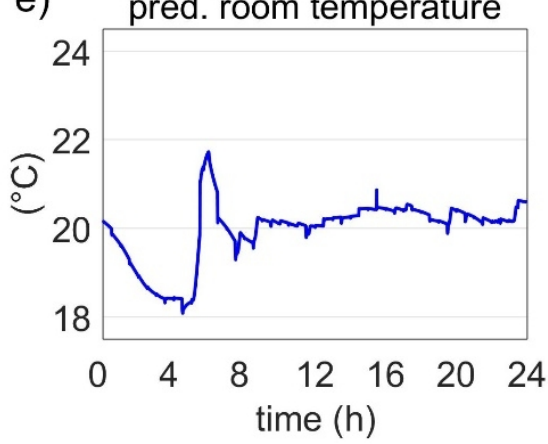

h)

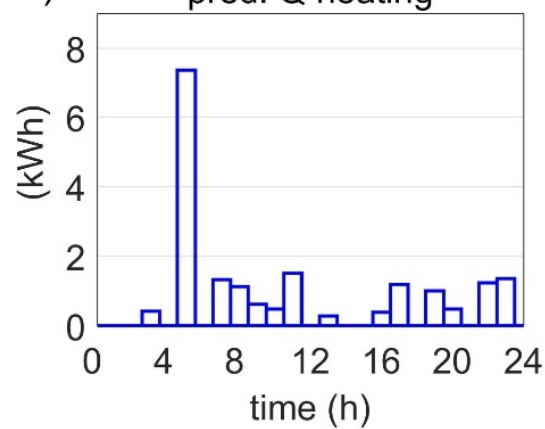

C) room temperature set points

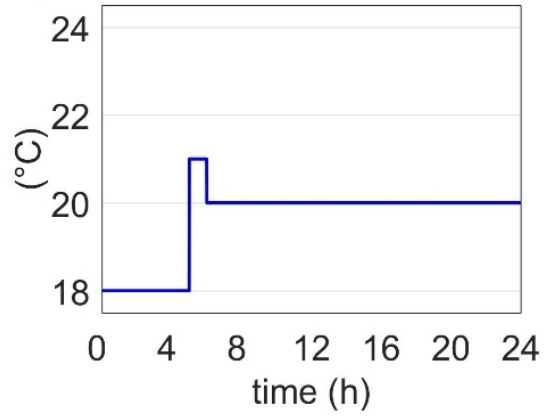

f) temperature diff. pred.- meas.

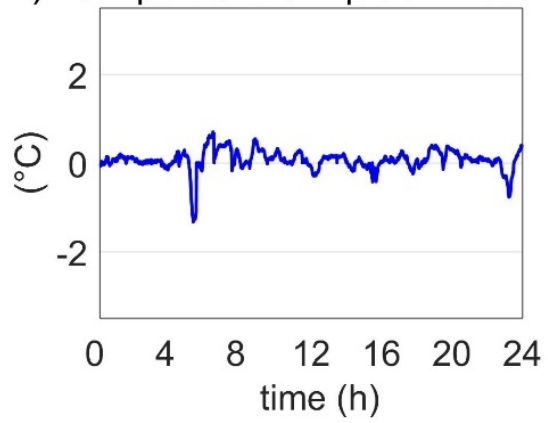

i) $Q$ heating diff. pred.- meas.

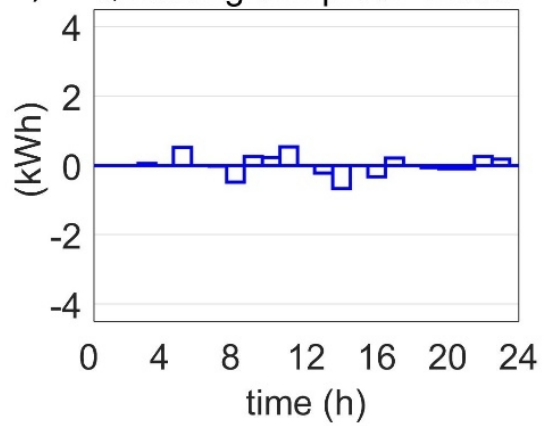

Figure 11. EMPC1; Hourly APX electricity prices including a) high-price periods and b) low-price periods; c) hourly room temperature set points; room temperature d) measured, e) predicted, and f) difference; heating demand $\left(Q_{\text {heating }}\right) g$ ) measured, h) predicted, and i) difference. 
Table 2. Summary results for EMPC1.

\begin{tabular}{cccc}
\hline Results & MPC predicted & MPC measured & Reference case \\
\hline$J($ Euro cent) & 12.43 & 12.86 & 13.85 \\
$Q_{\text {heating }}(\mathrm{kWh})$ & 18.71 & 18.41 & 18.15 \\
$Q_{\text {el.cons. } H P-\text { grid }}(\mathrm{kWh})$ & 3.86 & 3.95 & 3.50 \\
$Q_{\text {el.cons.HP }-P V}(\mathrm{kWh})$ & 0.42 & 0.39 & 0.46 \\
$Q_{\text {el.gen.PV }}(\mathrm{kWh})$ & 5.44 & 5.75 & 5.75 \\
COP $(-)$ & 4.37 & 4.24 & 4.58 \\
$F F(-)$ & 0.44 & 0.42 & -0.89 \\
$\gamma_{\text {supply }}(-)$ & 0.08 & 0.07 & 0.08 \\
$\gamma_{\text {load }}(-)$ & 0.10 & 0.09 & 0.12 \\
\hline
\end{tabular}

\subsubsection{EMPC2}

EMPC2, designed to maximise the flexibility factor, the supply cover factor, and the load cover factor, was implemented and tested on 11 April 2017. Figure 12 shows the results of the weather forecasting and measurement data.
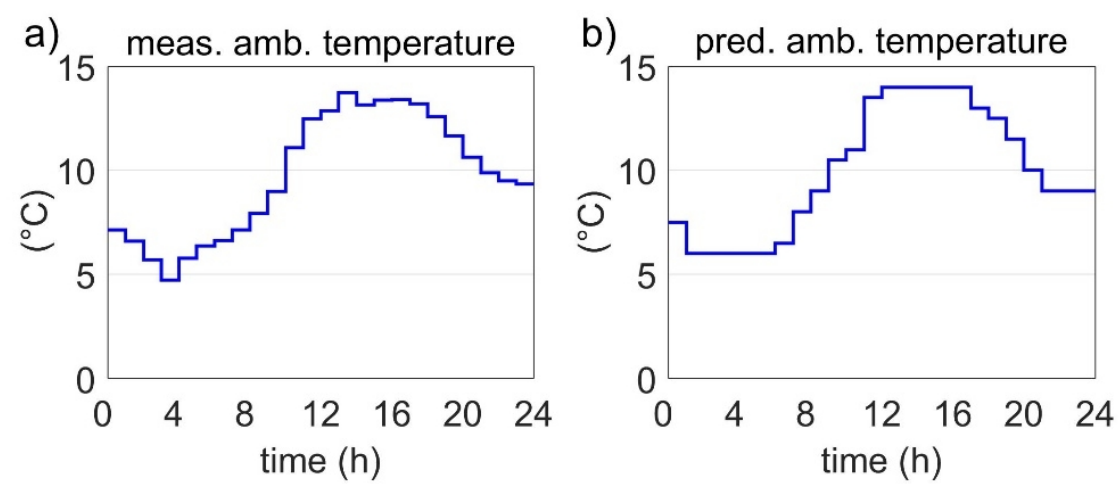

c) temperature diff. pred.- meas.
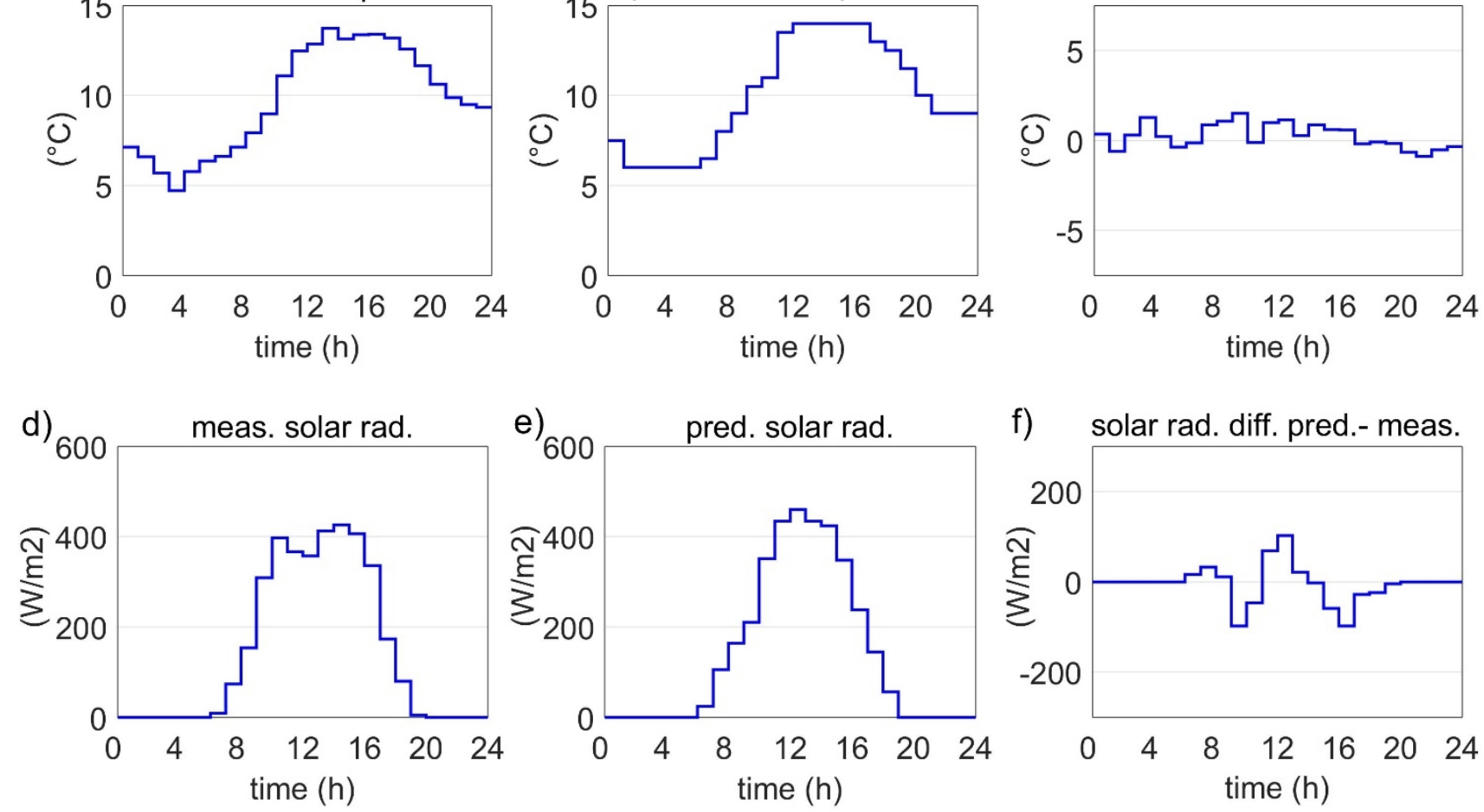

Figure 12. EMPC2; hourly ambient temperature a) measured, b) predicted, and c) difference; hourly solar radiation d) measured, e) predicted, and f) difference. 
A prediction performance was calculated for ambient temperature of RMSE $=0.71, \mathrm{MAE}=0.58, \mathrm{MAPE}=0.06$, $\mathrm{R}^{2}=0.94$, and $\mathrm{G}=0.76$ and for hourly solar radiation of $\mathrm{RMSE}=42, \mathrm{MAE}=25, \mathrm{MAPE}=0.25, \mathrm{R}^{2}=0.95$, and $\mathrm{G}=0.76$.

In addition to APX electricity prices $\left(C_{\text {el.cons.grid }}(t)\right)$, EMPC2 required the determination of the price of electricity consumed from PV generation $\left(C_{\text {el.cons.PV }}\right)$ and the price of electricity exported to the power grid $\left(C_{\text {el.feed in grid }}\right)$. For the test day, the electricity prices were assumed according to

$$
C_{\text {el.feed in grid }}(t)=-C_{\text {el.cons.grid }}(t)
$$

and

$C_{\text {el.cons.PV }}(t)=-5\left(C_{\text {el.cons.grid }}(t)\right)$.

The results of the control decisions of EMPC2 are shown in Figure 13. A prediction performance was calculated for room temperature of $\mathrm{RMSE}=0.27, \mathrm{MAE}=0.18$, MAPE $=0.01, \mathrm{R}^{2}=0.93$, and $\mathrm{G}=0.73$ and for heating demand of $\mathrm{RMSE}=0.19, \mathrm{MAE}=0.10, \mathrm{MAPE}=0.28, \mathrm{R}^{2}=0.99$, and $\mathrm{G}=0.89$. During low-price periods $(\mathrm{APX}$ price), the HP provided heating to the building (5:00 - 6:00). Between 15:00 and 17:00 the optimal temperature set point was raised to $22{ }^{\circ} \mathrm{C}$. During this time slot, APX prices were relatively low and PV power generation was relatively high compared to the daily average. Using EMPC2 resulted in increases of flexibility factor from -0.88 to 0.67 , supply cover factor from 0.04 to 0.13 , and load cover factor from 0.07 to 0.16 , as shown in Table 3.

Equation 16 and 17 assume a constant relation between APX electricity prices $\left(C_{\text {el.cons.grid }}(t)\right)$, prices of direct electricity consumption from PV $\left(C_{\text {el.cons.PV }}\right)$ and prices of electricity exported to the power grid $\left(C_{\text {el.feed in grid }}\right)$. Additional simulations were performed to analyse the effect of price variations. Figure 14 illustrates the results of varying $C_{\text {el.cons.PV }} /-C_{\text {el.cons.grid }}$ between a value of 1 and 15 while keeping $C_{\text {el.feed in grid }}=-C_{\text {el.cons.grid }}$ constant. 

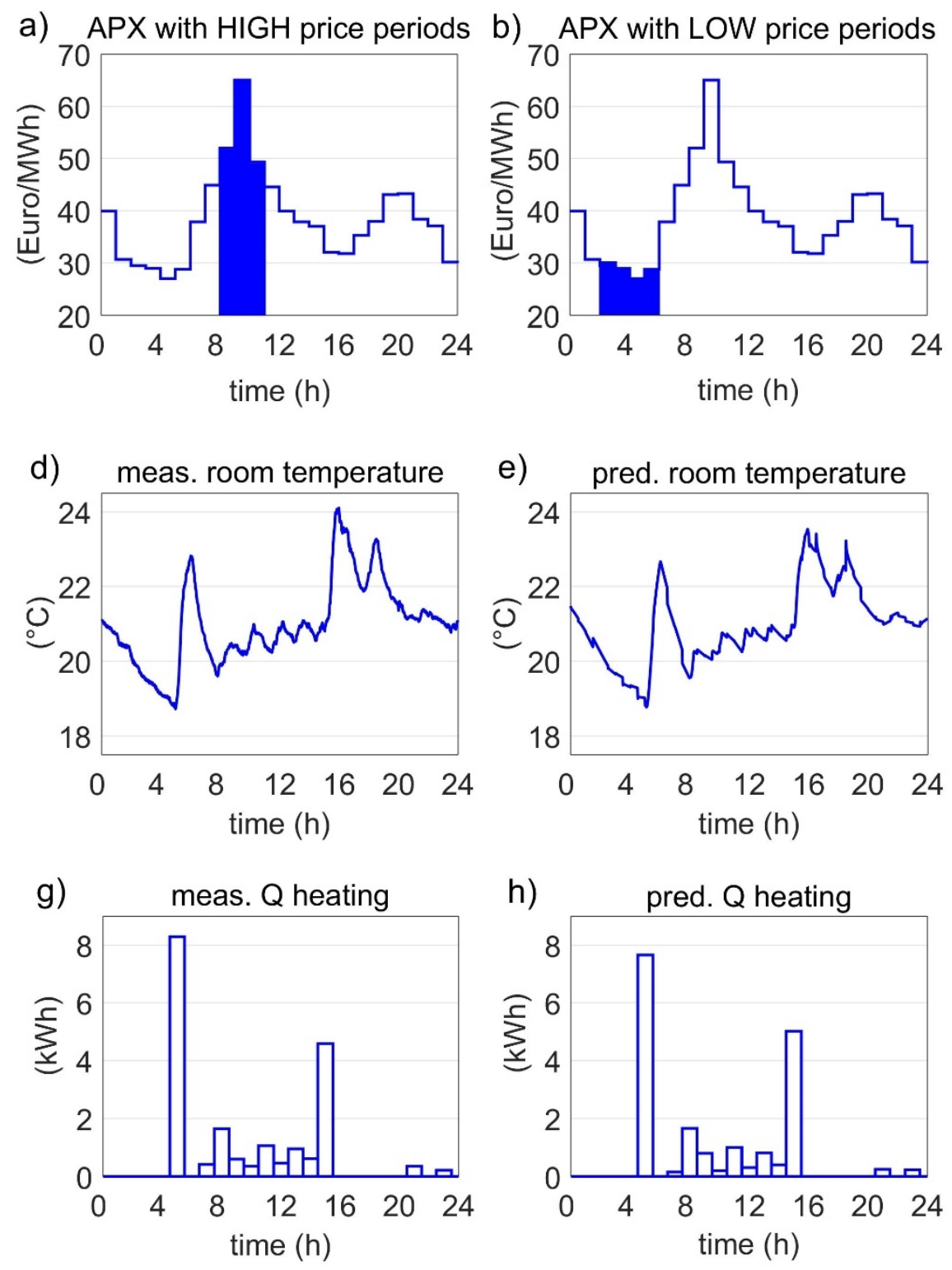

c) room temperature set point

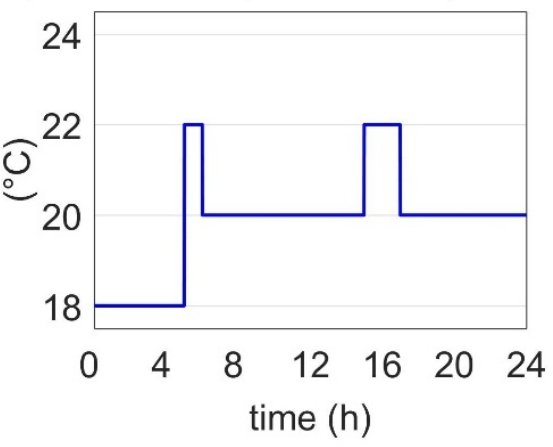

f) temperature diff. pred.- meas.

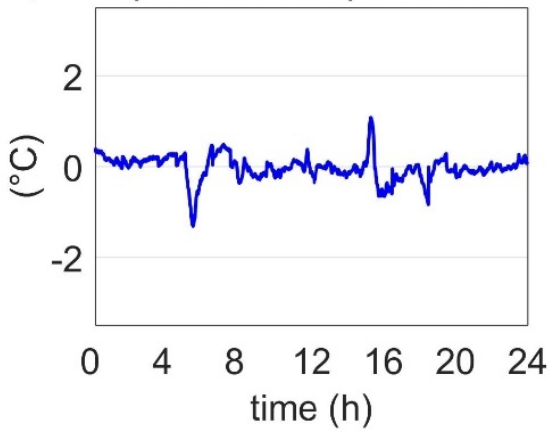

i) $Q$ heating diff. pred.- meas.

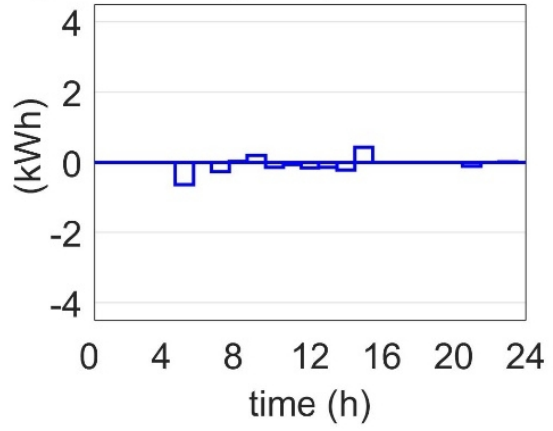

Figure 13. EMPC2; Hourly APX electricity prices including a) high-price periods and b) low-price periods; c) hourly room temperature set points; room temperature d) measured, e) predicted, and f) difference; heating demand g) measured, h) predicted, and i) difference. 
Table 3. Summary results for EMPC2.

\begin{tabular}{cccc}
\hline Results & MPC predicted & MPC measured & Reference case \\
\hline$J($ Euro cent) & 13.69 & 13.85 & 14.28 \\
$Q_{\text {heating }}(\mathrm{kWh})$ & 19.53 & 19.33 & 16.13 \\
$Q_{\text {el.cons.HP }- \text { grid }}(\mathrm{kWh})$ & 4.05 & 4.25 & 3.61 \\
$Q_{\text {el.cons.HP }-P V}(\mathrm{kWh})$ & 0.81 & 0.82 & 0.28 \\
$Q_{\text {el.gen.PV }}(\mathrm{kWh})$ & 7.15 & 6.56 & 6.56 \\
COP $(-)$ & 4.02 & 3.76 & 4.15 \\
$F F(-)$ & 0.68 & 0.67 & -0.88 \\
$\gamma_{\text {supply }}(-)$ & 0.11 & 0.13 & 0.04 \\
$\gamma_{\text {load }}(-)$ & 0.17 & 0.16 & 0.07 \\
\hline
\end{tabular}

a)

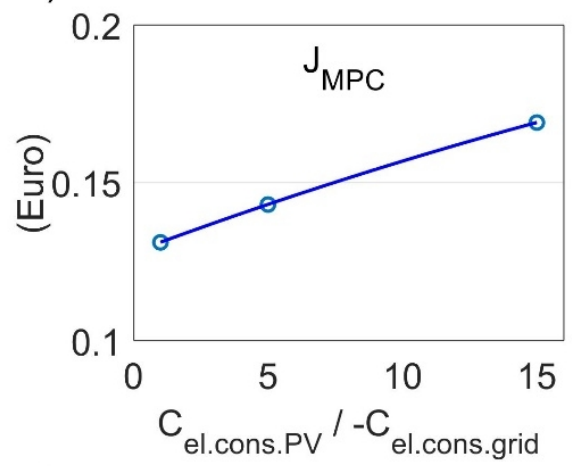

c)

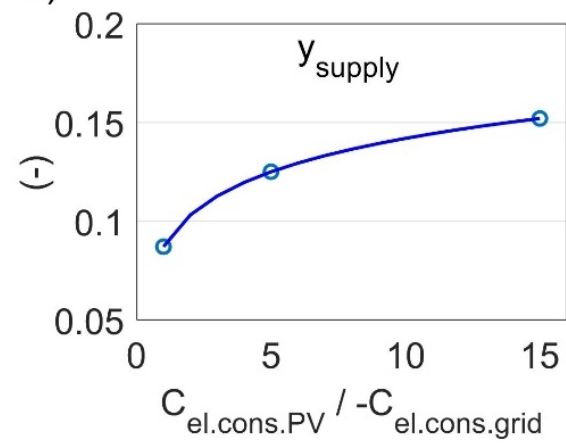

b)

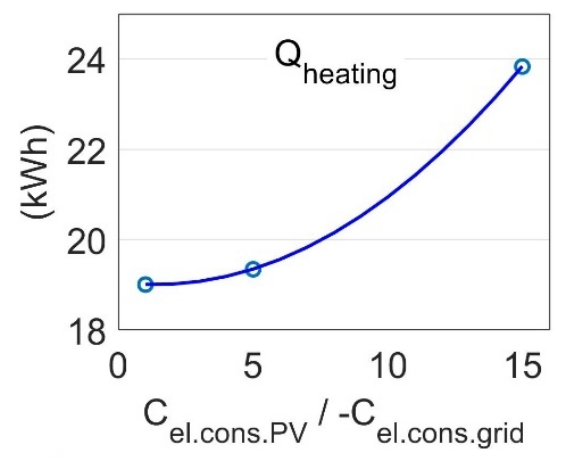

d)

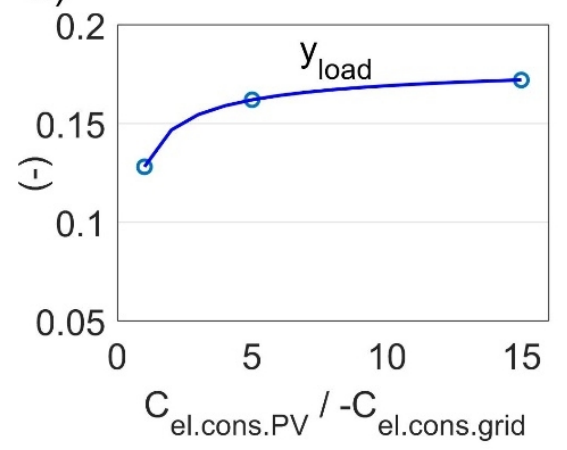

Figure 14. EMPC2; Price variations by changing $C_{\text {el.cons.PV }} /-C_{\text {el.cons.grid }}$ and assuming $C_{\text {el.feed in grid }}=-C_{\text {el.cons.grid }}$; a) daily operational electricity costs $\mathrm{J}_{\mathrm{EMPC}}$; b) daily heating energy $\mathrm{Q}_{\text {heating }}$; c) supply cover factor $\mathrm{y}_{\text {supply }}$ (selfconsumption); d) load cover factor $\mathrm{y}_{\text {supply }}$ (self-generation). 


\section{DISCUSSION}

An economic model predictive controller was implemented in a Dutch residential building. This controller included day-ahead electricity prices. The next step will be to incorporate intraday electricity prices to be able to adapt to short-term variations, as recommended by Heldegaard et al. [73]. The EMPC also integrated weather forecasting and prediction of building and heating system dynamics. The EMPC consisted of models using artificial neural networks. ANNs are black-box models which are formulated without using any physical equations. An advantage of ANNs is their ability to deal with nonlinear dynamics. A disadvantage is that they require large data sets for validation. In the present study, four months of measurement data (January-April 2017) were used to identify and validate the black-box models representing the building dynamics and the heating system. A ten-year data set was used to identify the black-box model for forecasting the global and horizontal solar radiation. During the test days, the ANN which forecasts solar radiation achieved a prediction performance of RMSE of 37-42, MAE of 24-25, MAPE of $0.25, R^{2}$ of $0.95-0.96$, and $G$ of $0.76-0.79$, which was less accurate than the prediction performance during the validation phase of RMSE $=25, M A E=13$, MAPE $=0.19, R^{2}=0.98$, and $G=0.87$. The decrease in prediction performance during test days was because of uncertainty in the forecasts of ambient temperature, precipitation, sunshine hours, cloud cover, relative humidity, and air pressure. The forecast of these parameters was retrieved from a professional forecasting service that provided hourly data. A shorter time step for predictions may increase the prediction accuracy [57]. However, shorter prediction time steps require a larger state space for the optimisation and thus increase the MPC computational time.

During the EMPC1 test day, no direct solar radiation affected the indoor climate. During the EMPC2 test day, direct solar radiation was observed at 18:00 (Figure $13 \mathrm{~d}$, e and f), resulting in a steep increase in room temperature and a reduction of prediction accuracy (delta $\mathrm{T}$ of up to $1 \mathrm{~K}$ ). It is observed that steep, short-term room temperature changes are less accurately predicted (delta $\mathrm{T}$ of up to $1.5 \mathrm{~K}$ in the first $10 \mathrm{~min}$ of heating with set point changes). However, the overall prediction performance for room temperature of RMSE of $0.24-$ 0.27, MAE of $0.16-0.18$, MAPE of $0.01, R^{2}$ of $0.89-0.93$, and $G$ of $0.66-0.73$ was in good agreement with other studies [34-36,50,67], as was the prediction performance for heating consumption of RMSE of $0.19-0.26$, MAE of $0.10-0.17$, MAPE of $0.28-0.30, R^{2}$ of $0.97-0.99$, and $G$ of $0.82-0.89$.

During the learning and validation phase of the MPC, the thermal heating power varied between $8 \mathrm{~kW}$ and 20 $\mathrm{kW}$, and a maximum of three on/off cycles of the heating system per hour were observed. Compared to conventional HPs in heating systems, the number of on/off cycles is reasonable. For the future, the number of on/off cycles is less critical when using inverter-controlled HPs that modulate heating power by regulating the compressor speed $[27,74]$. In the present study, a virtual inverter-controlled HP was assumed and simulated using a regression model which fit manufacturers' data. This modelling approach was sufficient for simulation studies to represent the performance of the HP [75]. For experimental case studies with real HPs, more sophisticated and full dynamic modelling approaches are recommended, for instance approaches using ANNs [75]. A similar conclusion is made for determining realistic performance measures of real PV panels in the 
control of building energy management systems [76]. The study [76] provides an extensive review of ANNs applied to solar energy systems, including PV. The authors in [76] suggest the use of ANN and machinelearning approaches to solar energy systems to reduce the financial expenses for modelling.

During the learning and validation phase of the MPC, a maximum, virtual PV power of $1 \mathrm{~kW}$ was calculated. From Table 2 and 3 , it can be seen that the amount of daily electrical energy provided by the virtual PV $\left(Q_{\text {el.gen.PV }}\right.$ ) was higher than the daily electricity consumption of the virtual HP $\left(Q_{\text {el.cons.HP }}\right)$. In contrast, the calculated selfconsumption varied between $7 \%$ and $25 \%$. This was primarily because the maximal PV power was always lower than the HP's electrical power consumption. A simple solution could be the installation of an electrical battery that could compensate for this mismatch. The electrical battery could be directly fed by the PV, and the battery's state of charge could be added as state variable to the MPC. An integration into the MPC as an additional control variable is not required.

In the tested MPC, deterministic profiles of occupancy and of window and curtain openings were used. Occupants were asked to follow a predefined schedule for opening of windows and curtains during the MPC experimental phase. In a next step, occupants' behaviour will be incorporated using a stochastic approach, as suggested by Wang et al. [16], to consider the uncertainty of energy flexibility that is due to the uncertainty of occupancy.

\section{CONCLUSION}

In the present paper, an experimental case study was presented of an MPC implemented in a residential building. An ANN-MPC approach was used to represent the dynamical behaviour of the heating systems and the building. Another ANN model was developed for weather forecasting to obtain global and horizontal solar radiation. All ANN models and the ANN-MPC were validated and tested, showing good prediction performance. The application of ANN models can be recommended for future identification of the dynamics of buildings and heating systems and for weather forecasting. The application of ANN-MPC can be recommended as a generic approach for optimal control of energy usage in energy systems in residential buildings. As a next step, it is important to adapt this generic methodology to other residential buildings. Further experimental case studies are required that compare MPC implementations, including performance evaluation of conventional and flexibility indicators.

This paper also introduced an EMPC approach to optimise demand flexibility. For this approach, operational costs of energy usage were associated with demand flexibility, which was represented by these flexibility indicators: flexibility factor, supply cover factor, and load cover factor. The operational costs were (1) the costs of consuming electricity from the grid, (2) the costs of consuming electricity from on-site PV power generation, and (3) the costs delivering electricity from on-site PV power generation to the grid. By taking into account the operational costs of energy usage, one objective function can be created, and demand flexibility can be optimised. As an example, assuming positive prices for electricity consumption from the grid, negative prices 
for electricity consumption from on-site PV generation, and negative prices for grid feed-in from on-site PV power generation resulted in an increase of flexibility factor, supply cover factor (self-consumption), and load cover factor (self-generation). This generic approach offers the possibility to regulate on-site generation, grid consumption, and grid feed-in. The methodology can be adapted to flexibility indicators which are associated with the costs of energy usage.

\section{ACKNOWLEDGEMENT}

This work was supported by BAM Techniek Energy Systems bv and BAM Bouw en Techniek Innovatie. This work was also part of the research activities of IEA EBC Annex 67 Energy Flexible Buildings. 


\section{APPENDIX - Performance metrics}

$i$ is the sample number, $n$ is the total number of samples, $e$ is the estimated data, $o$ is the output, $\bar{o}$ is the mean output

Root-Mean-Square Error

$R M S E=\sqrt{\frac{1}{n} \sum_{i=1}^{n}\left(e_{i}-o_{i}\right)^{2}}$

Mean Absolute Error

$M A E=\frac{1}{n} \sum_{i=1}^{n}\left|e_{i}-o_{i}\right|$

Mean Absolute Percentage Error

$M A P E=\frac{1}{n} \sum_{i=1}^{n}\left|\frac{\left|e_{i}-o_{i}\right|}{o_{i}}\right|$

Coefficient of Determination

$R^{2}=1-\frac{\sum_{i=1}^{n}\left(o_{i}-e_{i}\right)^{2}}{\sum_{i=1}^{n}\left(o_{i}-\bar{o}\right)^{2}}$

Goodness of Fit

$G=1-\frac{\sqrt{\sum_{i=1}^{n}\left(e_{i}-o_{i}\right)^{2}}}{\sqrt{\sum_{i=1}^{n}\left(o_{i}-\frac{1}{n} \sum_{i=1}^{n} o_{i}\right)^{2}}}$ 


\section{REFERENCES}

[1] International Energy Agency. Renewables information: Overview. 2017.

[2] Lund PD, Lindgren J, Mikkola J, Salpakari J. Review of energy system flexibility measures to enable high levels of variable renewable electricity. Renew Sustain Energy Rev 2015;45:785-807. doi:10.1016/j.rser.2015.01.057.

[3] Gelazanskas L, Gamage KAA. Demand side management in smart grid: A review and proposals for future direction. Sustain Cities Soc 2014;11:22-30. doi:10.1016/j.scs.2013.11.001.

[4] De Coninck R, Helsen L. Quantification of flexibility in buildings by cost curves - Methodology and application. Appl Energy 2016;162:653-65. doi:10.1016/j.apenergy.2015.10.114.

[5] Finck C, Li R, Kramer R, Zeiler W. Quantifying demand flexibility of power-to-heat and thermal energy storage in the control of building heating systems. Appl Energy 2018;209:409-25. doi:10.1016/j.apenergy.2017.11.036.

[6] Li R, Dane G, Finck C, Zeiler W. Are building users prepared for energy flexible buildings?-A large-scale survey in the Netherlands. Appl Energy 2017;203. doi:10.1016/j.apenergy.2017.06.067.

[7] Jensen S $\varnothing$, Marszal-Pomianowska A, Lollini R, Pasut W, Knotzer A, Engelmann P, et al. IEA EBC Annex 67 Energy Flexible Buildings. Energy Build 2017;155:25-34. doi:10.1016/j.enbuild.2017.08.044.

[8] Reynders G, Amaral Lopes R, Marszal-Pomianowska A, Aelenei D, Martins J, Saelens D. Energy flexible buildings: An evaluation of definitions and quantification methodologies applied to thermal storage. Energy Build 2018;166:372-90. doi:10.1016/j.enbuild.2018.02.040.

[9] Stinner S, Huchtemann K, Müller D. Quantifying the operational flexibility of building energy systems with thermal energy storages. Appl Energy 2016;181:140-54. doi:10.1016/j.apenergy.2016.08.055.

[10] Salpakari J, Lund P. Optimal and rule-based control strategies for energy flexibility in buildings with PV. Appl Energy 2016;161:425-36. doi:10.1016/j.apenergy.2015.10.036.

[11] Vanhoudt D, Geysen D, Claessens B, Leemans F, Jespers L, Van Bael J. An actively controlled residential heat pump: Potential on peak shaving and maximization of self-consumption of renewable energy. Renew Energy 2014;63:531-43. doi:10.1016/j.renene.2013.10.021.

[12] Fischer D, Madani H. On heat pumps in smart grids: A review. Renew Sustain Energy Rev 2017;70:342-57. doi:10.1016/j.rser.2016.11.182.

[13] Nuytten T, Moreno P, Vanhoudt D, Jespers L, Solé A, Cabeza LF. Comparative analysis of latent thermal energy storage tanks for micro-CHP systems. Appl Therm Eng 2013;59:542-9. doi:10.1016/j.applthermaleng.2013.06.023.

[14] Clauß J, Stinner S, Sartori I, Georges L. Predictive rule-based control to activate the energy flexibility of Norwegian residential buildings: Case of an air-source heat pump and direct electric heating. Appl Energy 2019;237:500-18. doi:10.1016/J.APENERGY.2018.12.074.

[15] Arteconi A, Hewitt NJ, Polonara F. State of the art of thermal storage for demand-side management. Appl Energy 2012;93:371-89. doi:10.1016/j.apenergy.2011.12.045.

[16] Wang A, Li R, You S. Development of a data driven approach to explore the energy flexibility potential of building clusters. Appl Energy 2018;232:89-100. doi:10.1016/j.apenergy.2018.09.187.

[17] Reynders G, Diriken J, Saelens D. Generic characterization method for energy flexibility: Applied to structural thermal storage in residential buildings. Appl Energy 2017;198:192-202. doi:10.1016/j.apenergy.2017.04.061.

[18] Junker RG, Azar AG, Lopes RA, Lindberg KB, Reynders G, Relan R, et al. Characterizing the energy flexibility of buildings and districts. Appl Energy 2018;225:175-82.

doi:10.1016/j.apenergy.2018.05.037.

[19] Salpakari J, Mikkola J, Lund PD. Improved flexibility with large-scale variable renewable power in cities through optimal demand side management and power-to-heat conversion. Energy Convers Manag 2016;126:649-61. doi:10.1016/j.enconman.2016.08.041.

[20] Clauß J, Finck C, Vogler-Finck P, Beagon P. Control strategies for building energy systems to unlock demand side flexibility - A review. 15th Int. Conf. Int. Build. Perform. Simul. Assoc., 2017, p. 611-20.

[21] Finck C, Clauß J, Vogler-Finck P, Beagon P, Zhan K, Kazmi H. Review of applied and tested control possibilities for energy flexibility in buildings Review of applied and tested control possibilities for energy flexibility in buildings. 2018. doi:10.13140/RG.2.2.28740.73609. 
[22] Salom J, Marszal AJ, Widén J, Candanedo J, Lindberg KB. Analysis of load match and grid interaction indicators in net zero energy buildings with simulated and monitored data. Appl Energy 2014;136:119-31. doi:10.1016/j.apenergy.2014.09.018.

[23] Masy G, Georges E, Verhelst C, Lemort V. Smart grid energy flexible buildings through the use of heat pumps and building thermal mass as energy storage in the Belgian context. Sci Technol Built Environ 2015;21:6:800-11. doi:10.1080/23744731.2015.1035590.

[24] Le Dréau J, Heiselberg P. Energy flexibility of residential buildings using short term heat storage in the thermal mass. Energy 2016;111:991-1002. doi:10.1016/j.energy.2016.05.076.

[25] Luthander R, Widén J, Nilsson D, Palm J. Photovoltaic self-consumption in buildings: A review. Appl Energy 2015;142:80-94. doi:10.1016/j.apenergy.2014.12.028.

[26] Reynders G. Quantifying the impact of building design on the potential of structural storage for active demand response in residential buildings. 2015. doi:10.13140/RG.2.1.3630.2805.

[27] Péan TQ, Salom J, Costa-Castelló R. Review of control strategies for improving the energy flexibility provided by heat pump systems in buildings. J Process Control 2018. doi:10.1016/j.jprocont.2018.03.006.

[28] Zong Y, Böning GM, Santos RM, You S, Hu J, Han X. Challenges of implementing economic model predictive control strategy for buildings interacting with smart energy systems. Appl Therm Eng 2017;114:1476-86. doi:10.1016/j.applthermaleng.2016.11.141.

[29] Lindelöf D, Afshari H, Alisafaee M, Biswas J, Caban M, Mocellin X, et al. Field tests of an adaptive, model-predictive heating controller for residential buildings. Energy Build 2015;99:292302. doi:10.1016/j.enbuild.2015.04.029.

[30] Fiorentini M, Wall J, Ma Z, Braslavsky JH, Cooper P. Hybrid model predictive control of a residential HVAC system with on-site thermal energy generation and storage. Appl Energy 2017;187:465-79. doi:10.1016/j.apenergy.2016.11.041.

[31] Touretzky CR, Baldea M. Integrating scheduling and control for economic MPC of buildings with energy storage. J Process Control 2014;24:1292-300. doi:10.1016/j.jprocont.2014.04.015.

[32] Ma J, Qin SJ, Salsbury T. Application of economic MPC to the energy and demand minimization of a commercial building. J Process Control 2014;24:1282-91. doi:10.1016/j.jprocont.2014.06.011.

[33] Huang $\mathrm{H}$, Chen L, Hu E. A new model predictive control scheme for energy and cost savings in commercial buildings: An airport terminal building case study. Build Environ 2015;89:203-16. doi:10.1016/j.buildenv.2015.01.037.

[34] Afram A, Janabi-Sharifi F, Fung AS, Raahemifar K. Artificial neural network (ANN) based model predictive control (MPC) and optimization of HVAC systems: A state of the art review and case study of a residential HVAC system. Energy Build 2017;141:96-113. doi:10.1016/j.enbuild.2017.02.012.

[35] Afram A, Janabi-Sharifi F. Black-box modeling of residential HVAC system and comparison of gray-box and black-box modeling methods. Energy Build 2015;94:121-49. doi:10.1016/j.enbuild.2015.02.045.

[36] Huang H, Chen L, Hu E. A neural network-based multi-zone modelling approach for predictive control system design in commercial buildings. Energy Build 2015;97:86-97. doi:10.1016/j.enbuild.2015.03.045.

[37] Reynolds J, Rezgui Y, Kwan A, Piriou S. A zone-level, building energy optimisation combining an artificial neural network, a genetic algorithm, and model predictive control. Energy 2018. doi:10.1016/j.energy.2018.03.113.

[38] Wang Z, Srinivasan RS. A review of artificial intelligence based building energy use prediction: Contrasting the capabilities of single and ensemble prediction models. Renew Sustain Energy Rev 2017;75:796-808. doi:10.1016/j.rser.2016.10.079.

[39] Killian M, Kozek M. Implementation of cooperative Fuzzy model predictive control for an energyefficient office building. Energy Build 2018. doi:10.1016/j.enbuild.2017.11.021.

[40] Killian M, Kozek M. Ten questions concerning model predictive control for energy efficient buildings. Build Environ 2016. doi:10.1016/j.buildenv.2016.05.034.

[41] Viot H, Sempey A, Mora L, Batsale JC, Malvestio J. Model predictive control of a thermally activated building system to improve energy management of an experimental building: Part II Potential of predictive strategy. Energy Build 2018. doi:10.1016/j.enbuild.2018.04.062.

[42] Sturzenegger D, Gyalistras D, Morari M, Smith RS. Model Predictive Climate Control of a Swiss Office Building: Implementation, Results, and Cost-Benefit Analysis. IEEE Trans Control Syst Technol 2016. doi:10.1109/TCST.2015.2415411. 
[43] Yu N, Salakij S, Chavez R, Paolucci S, Sen M, Antsaklis P. Model-based predictive control for building energy management: Part II - Experimental validations. Energy Build 2017. doi:10.1016/j.enbuild.2017.04.027.

[44] Clauß J, Finck C, Vogler-Finck P, Beagon P. Control strategies for building energy systems to unlock demand side flexibility - A review. 15th Int. Conf. Int. Build. Perform. Simul. Assoc., 2017, p. 611-20.

[45] Floss A, Hofmann S. Optimized integration of storage tanks in heat pump systems and adapted control strategies. Energy Build 2015;100:10-5. doi:10.1016/j.enbuild.2015.01.009.

[46] Fuentes E, Waddicor DA, Salom J. Improvements in the characterization of the efficiency degradation of water-to-water heat pumps under cyclic conditions. Appl Energy 2016;179:778-89. doi:10.1016/j.apenergy.2016.07.047.

[47] Uhlmann M, Bertsch SS. Theoretical and experimental investigation of startup and shutdown behavior of residential heat pumps. Int J Refrig 2012;35:2138-49. doi:10.1016/j.ijrefrig.2012.08.008.

[48] Qu M, Fan Y, Chen J, Li T, Li Z, Li H. Experimental study of a control strategy for a cascade air source heat pump water heater. Appl Therm Eng 2017;110:835-43. doi:10.1016/j.applthermaleng.2016.08.176.

[49] Bertsekas DP. Dynamic programming and optimal control. Belmont, Mass.: Athena Scientific; 2005.

[50] Garnier A, Eynard J, Caussanel M, Grieu S. Predictive control of multizone heating, ventilation and air-conditioning systems in non-residential buildings. Appl Soft Comput J 2015;37:847-62. doi:10.1016/j.asoc.2015.09.022.

[51] Ferreira PM, Ruano AE, Silva S, Conceição EZE. Neural networks based predictive control for thermal comfort and energy savings in public buildings. Energy Build 2012;55:238-51. doi:10.1016/j.enbuild.2012.08.002.

[52] Magalhães SMC, Leal VMS, Horta IM. Modelling the relationship between heating energy use and indoor temperatures in residential buildings through Artificial Neural Networks considering occupant behavior. Energy Build 2017;151:332-43. doi:10.1016/j.enbuild.2017.06.076.

[53] Ruano AE, Crispim EM, Conceição EZE, Lúcio MMJR. Prediction of building's temperature using neural networks models. Energy Build 2006;38:682-94. doi:10.1016/j.enbuild.2005.09.007.

[54] Amrouche B, Le Pivert X. Artificial neural network based daily local forecasting for global solar radiation. Appl Energy 2014;130:333-41. doi:10.1016/j.apenergy.2014.05.055.

[55] Al Shamisi MH Al, Assi AH, Hejase HAN. Using MATLAB to develop artificial neural network models for predicting global solar radiation in Al Ain City - UAE. Eng Educ Res Using MATLAB 2011:219-38. doi:10.1104/pp.17.01693.

[56] Inman RH, Pedro HTC, Coimbra CFM. Solar forecasting methods for renewable energy integration. Prog Energy Combust Sci 2013;39:535-76. doi:10.1016/j.pecs.2013.06.002.

[57] Diagne M, David M, Lauret P, Boland J, Schmutz N. Review of solar irradiance forecasting methods and a proposition for small-scale insular grids. Renew Sustain Energy Rev 2013;27:6576. doi:10.1016/j.rser.2013.06.042.

[58] Afroz Z, Urmee T, Shafiullah GM, Higgins G. Real-time prediction model for indoor temperature in a commercial building. Appl Energy 2018. doi:10.1016/j.apenergy.2018.09.052.

[59] Afram A, Fung AS, Janabi-Sharifi F, Raahemifar K. Development of an accurate gray-box model of ubiquitous residential HVAC system for precise performance prediction during summer and winter seasons. Energy Build 2018. doi:10.1016/j.enbuild.2018.04.038.

[60] Mustafaraj G, Chen J, Lowry G. Thermal behaviour prediction utilizing artificial neural networks for an open office. Appl Math Model 2010. doi:10.1016/j.apm.2010.02.014.

[61] The Weather Company. Weather Forecast \& Reports - Long Range \& Local | Wunderground | Weather Underground. n.d. https://www.wunderground.com/ (accessed January 10, 2019).

[62] KNMI climate data. KNMI - Koninklijk Nederlands Meteorologisch Instituut n.d. http://www.knmi.nl (accessed January 10, 2019).

[63] Bird RE, Hulstrom RL. Simplified clear sky model for direct and diffuse insolation on horizontal surfaces. 1981. doi:10.2172/6510849.

[64] Vaz AGR, Elsinga B, van Sark WGJHM, Brito MC. An artificial neural network to assess the impact of neighbouring photovoltaic systems in power forecasting in Utrecht, the Netherlands. Renew Energy 2016;85:631-41. doi:10.1016/j.renene.2015.06.061.

[65] Yadav AK, Chandel SS. Solar radiation prediction using Artificial Neural Network techniques: A 
. Renew Sustain Energy Rev 2014;33:772-81. doi:10.1016/j.rser.2013.08.055.

[66] MathWorks - Deep Learning Toolbox - Modeling and Prediction with NARX and Time-Delay Networks n.d. https://www.mathworks.com (accessed January 10, 2019).

[67] Žáčeková E, Váňa Z, Cigler J. Towards the real-life implementation of MPC for an office building: Identification issues. Appl Energy 2014;135:53-62. doi:10.1016/j.apenergy.2014.08.004.

[68] NIBE. Air/water heat pump NIBE F2120. 2017.

[69] Solar Fabrik - Photovoltaic modules n.d. https://www.solar-fabrik.de/downloads (accessed January 10, 2019).

[70] Huld T, Gottschalg R, Beyer HG, Topič M. Mapping the performance of PV modules, effects of module type and data averaging. Sol Energy 2010;84:324-38. doi:10.1016/j.solener.2009.12.002.

[71] Fischer D, Lindberg KB, Madani H, Wittwer C. Impact of PV and variable prices on optimal system sizing for heat pumps and thermal storage. Energy Build 2016;128:723-33. doi:10.1016/j.enbuild.2016.07.008.

[72] Sartori I, Napolitano A, Voss K. Net zero energy buildings: A consistent definition framework. Energy Build 2012;48:220-32. doi:10.1016/j.enbuild.2012.01.032.

[73] Hedegaard RE, Pedersen TH, Petersen S. Multi-market demand response using economic model predictive control of space heating in residential buildings. Energy Build 2017;150. doi:10.1016/j.enbuild.2017.05.059.

[74] Dengiz T, Jochem P, Fichtner W. Demand response with heuristic control strategies for modulating heat pumps. Appl Energy 2019;238:1346-60. doi:10.1016/j.apenergy.2018.12.008.

[75] Underwood CP. Heat pump modelling. Elsevier Ltd; 2016. doi:10.1016/B978-0-08-1003114.00014-5.

[76] Elsheikh AH, Sharshir SW, Abd Elaziz M, Kabeel AE, Guilan W, Haiou Z. Modeling of solar energy systems using artificial neural network: A comprehensive review. Sol Energy 2019;180:622-39. doi:10.1016/j.solener.2019.01.037. 